\title{
REGULATORY ANALYSIS IN CORPORATE LAW
}

\author{
Martin Petrin*
}

Drawing from recent experiences in the $U S, U K$, and $E U$, this article examines regulatory analysis of corporate law policies. It suggests that regulatory analysis, as currently understood and applied in this area, suffers from severe weaknesses. The effects of proposed corporate law policies are often particularly difficult to predict and even more difficult to quantify, which negatively impacts analytical reliability. Moreover, given its nature and interconnections with politics, corporate law is less amenable to purely technocratic assessments than other areas of law. Based on three case studies, the article explores these problems. It outlines a revised 'procedural' view, suggesting that regulatory analysis in corporate law should be understood primarily as a process for enhancing information, transparency, and monitoring, independently from specific normative criteria. This leads to several implications. In short, regulatory analysis should combine quantified analysis with leeway for regulatory judgment and focus on increased consultation, critical engagement, review, and transparency as the dominant guiding factors.

Keywords: Regulatory analysis, impact analysis, cost benefit, corporate law, regulation

\footnotetext{
${ }^{*}$ UCL Faculty of Laws. The author is grateful to Professor David Kershaw and the anonymous referee for their insightful comments. Earlier versions of this article were presented at the National Business Law Scholars Conference at Loyola Law School, Los Angeles and the Centre for Corporate and Commercial Law at the University of Cambridge. I am thankful to participants at these events and for discussions and comments from Iris Chiu, Eilís Ferran, Maria Lee, and Marc Moore. Unless otherwise stated, all URLs were last accessed 10 March 2016.
} 


\section{(A) INTRODUCTION}

Legislatures and regulators in many countries have long been required to assess ex ante the potential consequences of proposed laws and regulations through various forms of regulatory analysis (hereinafter 'RA') ${ }^{1}$. Only upon a satisfactory outcome of these analyses may regulators implement new laws, underscoring the importance of RA in the legislative process. In particular due to its strong quantitative elements, RA has attracted both academic support and criticism. This article contributes to this discussion, focusing however on a more recent development, in which RA has begun to affect core areas of corporate and corporate governance law $^{2}$. Drawing from selected case studies in the United States, the United Kingdom, and the European Union, the article thus explores the application and avenues for further development of RA in the corporate law context, which despite its significance has not previously been examined in the UK.

${ }^{1}$ See C. Radaelli \& F. de Francesco, Regulatory Impact Assessment, in: The Oxford Handbook of Regulation, R. Baldwin et al., eds. (Oxford: OUP, 2010) 279 (stating that RA 'has spread throughout the globe'); R. Baldwin et al., Understanding Regulation (Oxford: OUP, 2012) 315319. For example, almost every OECD member state has now adopted some form of RA. 'Regulatory Impact Analysis,' http://www.oecd.org/gov/regulatory-policy/ria.htm.

${ }^{2}$ In this article, the term 'corporate law' will be used in a broad sense, encompassing both traditional corporate (or 'company') law and 'corporate governance law'. On the potential differences between these two and related terminology, see M. T. Moore, Corporate Governance in the Shadow of the State (Oxford: Hart Publishing, 2013) 12-14. As such, 'corporate law' may also overlap with aspects of financial and securities regulation, such as evidenced by the SEC's proxy access rule, which related to board composition and will be discussed below. 
The article proceeds as follows: In order to provide a foundational basis, the first part begins by defining the concept of RA and outlining the legal frameworks within which it operates in the three jurisdictions. This part also discusses various functions that are most commonly attributed to RA in general.

In the second part, the article shifts to an examination of three recent examples. First, it considers the US Securities and Exchange Commission's rule on proxy access and its controversial cost-benefit analysis of provisions designed to affect the composition of corporate boards. Second, the article explores the role of RA in the UK's latest executive remuneration reforms, which entail the question of which corporate constituency should be ultimately in charge of executives' salaries. Third, RA will be discussed in the context of EU provisions on non-financial corporate disclosure, an area that in part touches upon contentious corporate social responsibility questions.

Drawing from an analysis of these case studies, the article's final part provides an assessment of RA in corporate law. It suggests that while this tool may be useful, the inherent uncertainties in measuring the impact of corporate law policies as well as the biases affecting RA mean that its role is different from what it is often perceived. In contrast to other areas with a more 'scientific' basis and (to a certain extent) ex ante measurable effects, such as health and safety law, the consequences of proposed corporate law policies - which have no connection to physical 'laws of nature' - are particularly difficult to predict and quantify. Contentious issues therefore may need to be decided based at least in part on expert or regulatory judgment. Moreover, and relatedly, corporate law is to a large degree influenced by politics, and regulatory analysis is embedded in the political process, which frames outcomes and is difficult to reconcile with purely 'evidence-based' 
lawmaking that is apolitical and technocratic in nature. Indeed, it creates a risk that RA may be deployed to clothe political judgments in the garb of technocratic neutrality.

While this article focuses on and adds to the literature on RA in corporate and financial law as key aspects of 'economic regulation', 3 there are other sectors with similar characteristics. The analysis and recommendations developed in this article can therefore be applied more broadly. The dividing line between areas that are more amenable to traditional RA - such as health and safety - and those that are not - such as corporate and financial law - can arguably be drawn based on the extent to which definite, exogenous factors or principles form the input for an assessment. ${ }^{4}$ In corporate and financial law, fewer such exogenous factors are available. ${ }^{5}$ Moreover, this area is characterised by its strong impact on various branches of the economy, intersections with societal and political issues, and its

${ }^{3}$ See F. Chittenden et al., Impact Assessment in the EU, in: Better Regulation, S. Weatherill, ed (Oxford: Hart Publishing, 2007) 272, defining 'economic regulation' as encompassing 'regulations that seek to alter the commercial and financial frameworks and markets'.

${ }^{4}$ See text to $n$ 153-160 (discussing, in part, Jeffrey Gordon's arguments in this respect). In these areas, it may also be possible to conduct experiments, which is not an option in other fields.

${ }^{5}$ Other examples (based on the policy areas for UK impact assessments) that may suffer from comparable problems in terms of RA include arts and culture; community and society; equality, rights and citizenship; foreign affairs; and trade and investment. 
particularly dynamic nature. ${ }^{6}$ These factors make corporate law RA especially challenging - although not 'sui generis" ${ }^{7}$ - and amplify problems that are also present in other areas.

Against this background, the article suggest that rather than a mechanical method to unearth the 'best' possible laws according to a normative criterion (such as varying conceptions of 'efficiency' or 'fairness'), RA should be conceptualised as mainly a procedural and informational tool that supplements open consideration of the political and policy judgments that underpin regulatory choices. As such, and contrary to common views of RA, the tool's main functions are increasing transparency and information for the public and regulators alike, providing participatory opportunities for interested parties, and facilitating monitoring of regulators. The article thereby offers an alternative viewpoint to recent scholarly works that either support or propose to abolish the current regime of RA in corporate and financial law. To conclude, the article discusses the revised view's normative consequences and measures to improve and better align RA with its model.

\footnotetext{
${ }^{6}$ See J. C. Coates, 'Cost-Benefit Analysis of Financial Regulation: Case Studies and Implications' (2015) 124 Yale Law Journal 882, 998-1003.

${ }^{7}$ On this, see also E. A. Posner \& E. G. Weyl, 'Cost-Benefit Analysis of Financial Regulation: A Response to Criticisms' (2015) 124 Yale Law Journal Forum 246, available at http://www.yalelawjournal.org/pdf/Posner-WeylPDF_ijby4z9e.pdf (countering arguments that CBA in financial regulation is different from other fields).
} 


\section{(A) BACKGROUND}

\section{(B) Terminology}

At the outset of this article, it is important to define RA as the subject matter at hand. The use of terminology in this area tends to be inconsistent, with at times overlapping concepts. The most commonly known method for assessing the impact of regulatory measures is cost-benefit analysis ('CBA'). Traditionally, CBA has a strong emphasis on monetary quantification. Originally, CBA was used in large infrastructure project evaluation. ${ }^{8}$ As such and in its strict sense, it serves the purpose of assessing proposed ventures by calculating their net present value or 'net benefit' as derived from a project's expected positive and negative cash flows. ${ }^{9}$ Only projects whose benefits outweigh their costs (that is have positive net benefits) would normally be found viable and worthwhile pursuing.

Subsequently, CBA found its way into the regulatory toolbox. In this context, the term CBA is now used in different ways. It can still refer to a rigid method of weighing quantitative costs and benefits of policy choices, with a view to identifying the option with

\footnotetext{
${ }^{8}$ A. C. M. Meuwese, Impact Assessment in EU Lawmaking (Alphen aan den Rijn: Kluwer Law International, 2008) 63; OECD, 'Cost-Benefit Analysis and the Environment: Executive Summary' (2006) 16, available at http://www.oecd.org/greengrowth/tools-evaluation/36190261.pdf.

${ }^{9}$ See OECD, n 8 above, 16. See also D. M. Driesen, 'Is Cost-Benefit Analysis Neutral?' (2006) 77 Colorado Law Review 335 (defining regulatory CBA as an estimate 'of the regulation's costs and of the monetary value economists associate with the harms the regulation will avoid').
} 
the highest net benefits. ${ }^{10}$ However, CBA is also used in a more 'casual' or broader sense, in which costs and benefits are considered but the end result is not necessarily geared towards net benefits. This can be referred to as a 'cost-benefit approach', which entails 'assessing a proposal in terms of its consequences in a consistent manner, albeit one that accepts the logic of detrimental effects and beneficial effects' and includes a qualitative or quantitative description of these effects. ${ }^{11}$ Alternatively, CBA itself can be defined in a way that allows for a consideration of qualitative and distributive aspects. ${ }^{12}$

Upon closer examination, it becomes evident that what is referred to as CBA in the regulatory context is frequently farther removed from strict CBA and closer to a broader

${ }^{10}$ Compare, for example, the D.C. Circuit's references to 'net benefits' in its evaluation of an SEC cost-benefit analysis in Business Roundtable v. SEC, 647 F.3d 1144, 1153, 1155 (D.C. Cir. 2011). This decision will be discussed in more detail further below.

${ }^{11}$ Meuwese, n 8 above, 63. In a similar, albeit critical vein, two scholars have recently used the concept of an 'informal cost benefit analysis,' which they characterise as 'an approach that recognises the presence of costs and benefits and acknowledges that regulation's benefits ought to exceed its costs but do not actually try to measure whether they do.' O. Ben-Shahar \& C. E. Schneider, 'The Futility of Cost Benefit Analysis in Financial Disclosure Regulation' (2014) 43 Journal of Legal Studies S253, S254.

${ }^{12}$ R. W. Hahn \& C. R. Sunstein, 'A New Executive Order for Improving Federal Regulation? Deeper and Wider Cost-Benefit Analysis' (2002) 150 University of Pennsylvania Law Review 1489, 1498-1499. See also M. D. Adler \& E. A. Posner, 'Rethinking Cost-Benefit Analysis' (1999) 109 Yale Law Journal 165, 172, noting that distributional considerations are external to ordinary CBA, whereas more ambitious versions may incorporate more sophisticated distributional weightings. 
cost-benefit approach. ${ }^{13}$ Moreover, CBA should not be - but often is - confused or used interchangeably with the terms 'impact analysis', 'impact assessment', 'regulatory assessment' and similar labels. ${ }^{14}$ In the US, for instance, the analyses that many agencies are required to conduct may be referred to as 'Impact Statements' or 'Regulatory Impact Analyses. ${ }^{, 15}$ In the EU and UK, the official expression for the method of evaluating the consequences of regulatory policies is now 'Impact Assessment.'

${ }^{13}$ For instance, as one commentator has noted, the EU Commission's impact analyses normally use a cost-benefit approach, not traditional or 'strict' CBA. Meuwese, n 8 above, 63.

${ }^{14}$ See also H. Pierce, 'Economic Analysis by Federal Financial Regulators'(2013) 9 Journal of Law, Economics \& Policy 569, 569 n 2 ('[C]ost-benefit analysis and benefit-cost analysis are commonly used as substitutes for economic analysis and regulatory analysis but ... a thorough regulatory analysis entails much more than simply weighing the costs and benefits of a proposed regulation.').

${ }^{15}$ See, for example, Office of Information and Regulatory Affairs, 'Regulatory Impact Analysis: A Primer', available at http://www.whitehouse.gov/sites/default/files/omb/inforeg/regpol/circular-a4_regulatory-impact-analysis-a-primer.pdf; Office of Management and Budget, 'Circular A-4' (2003), available at https://www.whitehouse.gov/omb/circulars_a004_a-4.

16 A. Alemanno \& A. Meuwese, 'Impact Assessment of EU Non-Legislative Rulemaking: The Missing Link in the "New Comitology"' (2013) 19 European Law Journal 76; Minister of State for Employment Relations and Postal Affairs, 'Regulatory Impact Assessments: 1st January to 30th June 2007' 1, available at www.gov.uk/government/uploads/system/uploads/attachment_data/file/243114/7297.pdf 
These concepts may include the balancing of costs and benefits, but are different in substance from what is traditionally called CBA. They generally allow for a broader view that goes far beyond the balancing of costs and benefits. Notably, such analyses also tend to place greater weight on qualitative considerations and may also focus on factors such as sustainability, environmental, and humanitarian or societal effects. They are therefore different from rigid cost-benefit balancing and purely net benefit-focused methodologies. ${ }^{17}$

In this article, the term RA will generally be used to refer collectively to the various methods and processes by which regulators assess laws and regulations in a structured manner, including $\mathrm{CBA}$ as well as the more encompassing concepts that fall under the terms cost-benefit approach, regulatory impact analysis, regulatory statement, and impact analysis. Moreover, the terms 'regulation' and 'regulator' should be understood in a broad sense that includes laws and legislative bodies, respectively.

${ }^{17}$ Indeed, as a recent EU commissioned study has noted, CBA is only one of many methodologies that can be used in conducting RA. Other methods, including cost-effectiveness analysis, least cost analysis, and various forms of multi-criteria analysis, can be more appropriate depending on the specific circumstances. A. Renda et al., Assessing the Costs and Benefits of Regulation (Brussels, 2013) 202 . 


\section{(B) Frameworks}

RA has its roots in the US, where it has been long embedded in the legal system ${ }^{18}$ and all three branches of government have engaged in various forms of cost-benefit balancing. ${ }^{19}$ Nevertheless, in the US context, RA now mostly pertains to the rulemaking process by agencies. ${ }^{20}$ Modern RA first emerged in the 1970s as a reaction to growing regulation in the environmental, health, and safety areas. ${ }^{21}$ Subsequently, it evolved in most part through legislation and a series of presidential executive orders that require most executive

${ }^{18}$ The comparison of costs and benefits by federal agencies dates back to at least the beginning of the 20th century, growing rapidly in importance over time. See P. Rose \& C. Walker, The Importance Of Cost-Benefit Analysis In Financial Regulation (2013), Report for the US Chamber of Commerce, 3-4, available at http://ssrn.com/abstract=2231314; Adler \& Posner, n 12 above, 169170; Hahn \& Sunstein, n 12 above, 1505.

${ }^{19}$ See Rose \& Walker, n 18 above, 4, 10. As evidenced by the famous Hand formula, cost-benefit considerations even extend to areas such as judicial definitions of the standard of care in tort law. United States v. Carroll Towing Co. 159 F.2d 169, 173 (2d. Cir. 1947). For a more UK-centred discussion of the roots and development of CBA, see D. Pearce, 'Cost-Benefit Analysis and Environmental Policy' (1998) 14 Oxford Review of Economic Policy 84.

${ }^{20}$ See Radalli \& de Francesco, n 1 above, 281, discussing RA in the United States in the context of delegated rulemaking and, following from this, through the lens of principal agent theory.

${ }^{21}$ G. F. Bishop \& M. A. Coffee, 'A Tale of Two Commissions, A Compendium of the Cost-Benefit Analysis Requirements Faced by the SEC \& CFTC' (2013) 32 Review of Banking \& Financial Law 565, 571; J. D. Guynn, 'The Political Economy of Financial Rulemaking after Business Roundtable' (2013) 99 Virginia Law Review 641, 644. 
departments and agencies to conduct RA and have mandated a centralised cost-benefit monitor, the Office of Information and Regulatory Affairs in the Office of Management and Budget, with reviewing these analyses. ${ }^{22}$

Most recently, President Obama's 2011 executive order reaffirmed, and in part modified, the governing principles. ${ }^{23}$ Notably, the executive order now adds that where appropriate and permitted by law, agencies may consider and discuss qualitatively values that are difficult or impossible to quantify, including equity, human dignity, fairness, and distributive impacts. ${ }^{24}$ In addition to the Presidential Orders, further guidance can be found in legislative instruments and internal guidelines, such as the ones issued by the $\mathrm{SEC}^{25}$.

${ }^{22}$ See Bishop \& Coffee, n 21 above, 571-576; J. N. Gordon, 'The Empty Call for Benefit-Cost Analysis in Financial Regulation'(2014) 43 Journal of Legal Studies 351, 355-358; Pierce, n 14 above, 571-572.

${ }^{23}$ Executive Order 13,563 (2011) 76 Fed. Reg. 3821 s 1(a)-(b).

${ }^{24}$ ibid s 1(c). This modification is particularly useful in situations where the regulator is required to pursue social or humanitarian objectives - such as in the US conflict minerals rule (see n 62 below) - and where previously only efficiency-based assessment criteria would have been permissible, leading to potential legal issues due to the divergence between regulatory goals and RA principles. For a critique of the new rules, see E. A. Posner, 'Obama's Cost-Benefit Revolution' (2014) The Republic, available at http://www.newrepublic.com/article/81990/obama-cost-benefit-revolution (suggesting that attempts to soften CBA's focus on quantification are problematic).

${ }^{25}$ US Securities and Exchange Commission, Current Guidance on Economic Analysis in SEC Rulemaking (2012), available at 
RA, in the form of 'Impact Assessments,' has now also 'taken centre stage in the preparation of legislation, rules and policies in the context of the EU over the last decade.'26 Impact assessments are part of the EU's broader 'Better Regulation' (now called 'Smart Regulation') initiative, which aims to improve and ensure the effectiveness of EU policies. ${ }^{27}$ Initially only a 'pre-political decision-making' tool that the EU Commission used to prepare legislative proposals and broader policy initiatives, the scope of RA has been extended to include non-legislative EU rulemaking. ${ }^{28}$ Also, in addition to its use at Commission level, RA is conducted by the European Parliament and European Council, with the different bodies' analyses being coordinated by an intra-institutional agreement. ${ }^{29}$

https://www.sec.gov/divisions/riskfin/rsfi_guidance_econ_analy_secrulemaking.pdf; National Center for Environmental Economics, Guidelines for Preparing Economic Analyses (2014), available at http://yosemite.epa.gov/ee/epa/eerm.nsf/vwAN/EE-0568-50.pdf/\$file/EE-0568-50.pdf.

${ }^{26}$ Alemanno \& Meuwese, n 16 above, 76.

${ }^{27}$ For an overview and key documents, see the European Commission's Smart Regulation portal at http://ec.europa.eu/smart-regulation/index_en.htm. On the development of the better regulation movement and its implications, see R. Baldwin, 'Is better regulation smarter regulation?' (2005) Public Law 485.

${ }^{28}$ Alemanno \& Meuwese, n 16 above, 76-79. See also European Commission, Impact Assessment Guidelines (2009) SEC(2009) 92 [hereinafter IA Guidelines 2009], which state that generally, impact assessments 'are necessary for the most important Commission initiatives and those which will have the most far-reaching impacts'.

29 The European Parliament and Council have committed to conducting their own impact assessments on substantive amendments to proposals submitted by the EU Commission. See Inter- 
$\mathrm{RA}$ in the EU is in large part governed by the Commission's Impact Assessment Guidelines. ${ }^{30}$ Key elements of an impact analysis under the Guidelines are a definition of the problem and reasons for intervention, the policy objectives that are being pursued and intended effects, the policy options that have been considered, the assessment of monetisable and non-monetisable impacts, a discussion and comparison of the options including the option of 'doing nothing' -, and proposals for monitoring and evaluation. ${ }^{31}$ The assessment is preceded by a consultation process for interested parties and the gathering of relevant expertise and data. The findings are presented in a draft report, which, after further scrutiny, will result in a final report and adopted proposal. ${ }^{32}$

The EU, similar to the US, also has an independent and centralised system to monitor RA, the Impact Assessment Board (IAB). ${ }^{33}$ The Board 'aims to improve the quality of the Commission's impact assessments by strengthening quality control and providing advice and support' and has a mandate to 'examine all impact assessments, which accompany Institutional Common Approach to Impact Assessment (IA), available at http://ec.europa.eu/smartregulation/impact/ia_in_other/docs/ii_common_approach_to_ia_en.pdf.

${ }^{30}$ IA Guidelines 2009, n 28 above. Note that there is an ongoing project in place to revise the current Guidelines. See 2014 Revision of the European Commission Impact Assessment Guidelines - Public Consultation Document, Annex I, available at http://ec.europa.eu/smartregulation/impact/docs/iag_pc_questionnaire_en.pdf.

${ }^{31}$ IA Guidelines 2009, n 28, Part II.

${ }^{32}$ ibid 7-12.

${ }^{33}$ See generally European Commission, Impact Assessment Board Report for 2013 (2013) 1-3, available at http://ec.europa.eu/smart-regulation/impact/key_docs/docs/iab_report_2013_en.pdf. 
Commission initiatives with significant impacts. ${ }^{34}$ Among other tasks, the Board issues recommendations on draft impact assessment reports. In principle, the Board's positive opinion is needed for an initiative to be tabled for adoption by the Commission.

The UK, like other EU member states, also relies increasingly on RA as part of its 'Better Regulation' framework. In 2007, the government replaced 'Regulatory Impact Assessments' with a revised 'Impact Assessment' tool, with a view to have a 'simpler, more transparent process that will be embedded in the earliest stage of policy making. ${ }^{35}$

UK impact assessments are conducted by governmental departments and executive agencies, ${ }^{36}$ as a matter of 'good practice' or, as the case may be, specific statutory or other requirements. ${ }^{37}$ Assessments are generally required for all forms of intervention, including primary or secondary (delegated) legislation as well as codes of practice or guidance. Although previously focused on regulations, including proposed European legislation, that were expected to increase or decrease costs on businesses, the third sector, or the public

\footnotetext{
${ }^{34}$ Impact Assessment Board (IAB) Mandate, available at http://ec.europa.eu/governance/impact/iab/docs/iab_mandate_annex_sec_2006_1457_3.pdf.

${ }^{35}$ Minister of State for Employment Relations and Postal Affairs, Regulatory Impact Assessments: 1st January to 30th June 2007 (2008) 1.

${ }^{36} \mathrm{HM}$ Treasury, The Green Book - Appraisal and Evaluation in Central Government (2003) 8.

${ }^{37}$ See, for example, Section 5A of the Utilities Act 2000, inserted by section 6 of the Sustainable Energy Act 2003, which requires the gas and electricity markets authority to carry out impact assessments.
} 
sector, ${ }^{38}$ the contemporary approach broadens the requirement for impact assessments to include policies that have an effect on the public or third parties. ${ }^{39}$

Guidance on how to conduct impact assessments is provided in documents such as the Green Book, ${ }^{40}$ the Practical Guidance for UK Government Officials, ${ }^{41}$ as well as in specific internal guidelines. ${ }^{42}$ In terms of substance, impact assessments at the UK level are similar to their EU level counterparts. ${ }^{43}$ UK impact assessments also go through several stages,

${ }^{38}$ See HM Government, Impact Assessment Guidance - When to do an Impact Assessment (2011) 1 (on file with author; the document has recently been removed from the government's website and is subject to change); Green Book, n 36 above, 8 (stating that 'the trigger for producing an RIA is that the proposal could affect businesses, charities or the voluntary sector').

39 See Department for Business, Innovation \& Skills (hereinafter BIS), Better Regulation Framework Manual - Practical Guidance for UK Government Officials (2015) 56 (defining an impact assessment in part as a tool 'to help develop policy by assessing and presenting the likely costs and benefits and the associated risks of a proposal that might have an impact on the public, business or civil society organisations, the environment and wider society').

${ }^{40}$ Green Book, n 36 above.

${ }^{41}$ BIS, n 39 above.

${ }^{42}$ For example, Ofgem, Impact Assessment Guidance (2013), available at https://www.ofgem.gov.uk/ofgem-publications/83550/impactassessmentguidance.pdf.

${ }^{43}$ See the official impact assessment template at https://www.gov.uk/government/uploads/system/uploads/attachment_data/file/278558/impactassessment-template.dot. 
including a consultation stage with interested parties and a review stage that culminates in the (non-binding) opinion by a reviewing body, the Regulatory Policy Committee. ${ }^{44}$

\section{(A) FunCtions}

At first glance, the idea of analysing the consequences of proposed policies makes intuitive sense and seems not to require further explanation. Nevertheless, identifying the precise justification for conducting RA has proven elusive, and even its utility is controversial. Thus, this part aims to provide a cross-jurisdictional overview of functions commonly attributed to $\mathrm{RA} .{ }^{45}$ It should be kept in mind, however, that functions may differ depending on the specific context and that the lines between some of them tend to be blurred.

44 See generally Regulatory Policy Committee: Business Plan 2013-14 (2012), available at https://www.gov.uk/government/uploads/system/uploads/attachment_data/file/253940/RPC-

Business-Plan-2013-14_copy.pdf. It should be noted that the RPC's involvement is now initiated at an early stage, allowing the Committee to continuously work with departments as they produce their assessments.

45 The following builds in part on Robert Ahdieh's exploration of the regulatory functions of CBA. R. B. Ahdieh, 'Reanalyzing Cost-Benefit Analysis: Toward a Framework of Function(s) and Form(s)' (2013) 88 New York University Law Review 1983, 2009-2023. For an overview of additional perspectives, see C. Dunlop et al., 'The many uses of regulatory impact assessment: A meta-analysis of EU and UK cases' (2012) 6 Regulation \& Governance 23, 24-28. For the purpose of this article, it is worth pointing out that many functions attributed to CBA are applicable to RA generally, given that CBA can be interpreted broadly. See text to $n$ 10-12 above. 


\section{(B) Efficiency and social welfare}

Given the prevalence of CBA as the default method to analyse regulatory actions, it is no surprise that a central function of RA is often seen as promoting 'efficiency', which is the traditional economic justification of CBA. In this regard, a distinction can be made between 'absolute efficiency' and 'relative efficiency'. The former is reflected in justifications of CBA that emphasise its potential to promote efficiency generally, whereas the latter - less ambitious explanation - pertains to conceptualisations of CBA that focus on its role in assisting regulators to choose the most efficient among several proposed policies. ${ }^{46}$

In any instance, the question then arises what constitutes efficiency. Traditionally, this is debated by reference to the familiar welfare economics concepts of Pareto or KaldorHicks efficiency, with the latter having formed the basis for modern CBA. ${ }^{47}$ Nevertheless, both concepts do not provide convincing justifications for CBA and, even less so, the broader concept of RA. In short, Pareto efficiency is unlikely to be achieved given its stringent requirements, while the normative value of Kaldor-Hicks optimality can be disputed given its reliance on solely hypothetical wealth transfers (but not real

\footnotetext{
${ }^{46}$ On priority setting in CBA, see Ahdieh, n 45 above, 2014-2016.

${ }^{47}$ See Adler \& Posner, n 12 above 169-170, 176-194; R.A. Posner, 'Cost-Benefit Analysis: Definition, Justification, and Comment on Conference Paper' (2000) 29 Journal of Legal Studies 1153, 1153-1156. A project is (1) Pareto efficient if it does not produce any losers and at least one individual gains from it; and (2) Kaldor-Hicks efficient if, in a hypothetical costless lump-sum redistribution, those that gain from a project could compensate those that are worse off, leading to a Pareto efficient outcome as a result.
} 
compensation) ${ }^{48}$ Moreover, even if CBA would be certain to advance efficiency (with the cost of conducting CBA included in the overall calculations), using efficiency alone as a guide may be unsuitable.

Thus, in light of these explanatory weaknesses, CBA has also been said to serve broader non-utilitarian goals. Adler and Posner have argued that CBA is properly understood as a welfarist tool that is justified by normative concerns, namely in the form of overall wellbeing measured against adjusted individual preferences, not efficiency. ${ }^{49}$

As Adler and Posner explain, efficiency-based CBA would result in undesirable outcomes in instances such as where preferences are distorted because they are uninformed or objectively undesirable, or where a policy would result in substantial wealth differentials. First, because efficiency concepts are linked to actual (as opposed to informed and undistorted) individual preferences,${ }^{50}$ a project may be deemed 'efficient' even if the underlying preferences suffer from defects. For example, a group of people may prefer a certain project based on misleading information that they were given. Unless they receive more complete information, the implemented project corresponds to their actual preferences and satisfies the efficiency requirement. Second, efficiency concepts fail to adjust for distortions caused by wealth distributions. Thus, assuming that a project results in substantial welfare gains for a small group and substantial welfare losses for a large group,

\footnotetext{
${ }^{48}$ See Adler \& Posner, n 12 above, 176-194 (rejecting traditional CBA justifications).

49 ibid 194-216; M. D. Adler \& E. A. Posner, 'Implementing Cost-Benefit Analysis When Preferences are Distorted' (2000) 29 Journal of Legal Studies 1105, 1108-1116.

${ }^{50}$ The 'gains' in Pareto and Kaldor-Hicks efficiency (see n 47 above) are commonly expressed in terms of a person's actual preferences. Adler \& Posner, n 49 above, 1105-1106.
} 
the project can still be 'efficient' if the gains - even marginally - surmount the losses. However, this does not account for potential negative effects associated with creating increased wealth differentials.

In a similar vein, Hahn and Sunstein have noted that '[r]egulation should ordinarily promote social welfare, and while social welfare might be promoted by regulations that fail cost-benefit analysis, cost-benefit analysis is an imperfect but useful and administrable proxy for the inquiry into the social welfare question. ${ }^{, 51}$ They also argue that distributional considerations should be taken into account, where appropriate, when CBA is carried out. ${ }^{52}$ Apart from these critiques, purely efficiency-based explanations also stand on weak ground for other reasons. At a basic and practical level, RA that exclusively relies on strict CBA would, without regard to any specific normative concerns, simply not allow projects to go forward whose costs exceed their benefits. ${ }^{53}$ This is reminiscent of the US approach and its formal requirement that benefits need to be larger than costs. ${ }^{54}$ Yet, even a strict net

${ }^{51}$ Hahn \& Sunstein, n 12 above, 1499.

${ }^{52}$ ibid 1500.

53 See Driesen, n 9 above, 390-92 (discussing the 'Optimality' and 'No Excess' criteria of regulatory efficiency); Executive Order 13,563 (2011) 76 Fed. Reg. 3821 (requiring that agencies 'consider' costs and benefits).

${ }^{54}$ Conversely, the EU does not formally impose such a requirement, noting that impact assessments are decision-making aids, not a substitute for political judgments. See European Commission, 'Communication on Impact Assessment' (2002) COM(2002) 3; I. Lianos \& M. Fazeka, 'The One and the Many: Elaborating a taxonomy of Impact Assessment practices in Europe' (2014) CLES Research Paper Series, 1/2014, available at http://www.ucl.ac.uk/cles/research-paper- 
benefit requirement is not free from difficulties. Apart from potential problems with quantification, the issues here include that it is not always clear which persons' benefits should be taken into account and, moreover, it may be questionable where and when costs and benefits should accrue in order to be deemed relevant.

For instance, in corporate law, should regulators focus solely on benefits for investors/shareholders or should they also include managers, employees, etc. in their analysis? What timeframe should be used in when conducting RA and should benefits that accrue abroad be taken into account $?^{55}$ Moreover, regulatory practice shows that RA does not prevent policies whose estimated or actual costs exceed their benefits, ${ }^{56}$ which further refutes the feasibility of an efficiency-based function of RA.

series/research-papers/cles-1-2014 (agreeing with the definition of impact assessments as a strategic tool that influences public authorities). Nevertheless, in practice the US approach is also less strict. For instance, even the former SEC Commissioner Troy Paredes has recently remarked that 'sometimes cost-benefit analysis isn't the thing that drives the decision-making.' Symposium, JOBS Act: The Terrible Twos - General Solicitation and Crowdfunding, the Next Frontier of Securities Regulation, 'Keynote Address' (2015) 20 Fordham Journal of Corporate and Financial Law 338, 340.

55 The EU may include impacts that fall outside of its territory in its impact assessment considerations. Similarly, see the SEC's recent Mineral Conflicts Rule, where the central benefit consisted of curbing human rights violations occurring abroad. Conflict Minerals Rule (2012) 77 Fed. Reg. 56,274.

${ }^{56}$ Hahn \& Sunstein, n 12 above, 1490-1494, provide a list of various US legislative projects, ranging from issues such as roadworker protection to air quality standards, with negative net 
Indeed, those who conduct and oversee RA do not adhere to a purely efficiency-driven or monetary net benefit approach. For instance, the US Office of Management and Budget advocates a mixed approach, combining a focus on social welfare improvements with priority setting and efficiency aspects. ${ }^{57}$ Similarly, UK impact assessments should cover the full range of economic, social and environmental effects, in line with the Green Book methodology. ${ }^{58}$ The Green Book expressly states that costs and benefits should be adjusted based on a distributional analysis and provides guidance on methodologies to be used in this respect, ${ }^{59}$ while the Better Regulation Framework further clarifies the nature of some of the social factors that departments should consider as part of an impact assessment.

benefits. See also E. A. Posner, 'Controlling Agencies with Cost-Benefit Analysis: A Positive Political Theory Perspective' (2002) 68 University of Chicago Law Review 1137, 1182-1186 (discussing inefficiency of regulations). The Office of Management and Budget reported that while the great majority of rules have net benefits, 'over the last decade, a few rules have net costs, typically as a result of legal requirements'. Office of Management and Budget, Draft 2013 Report to Congress on the Benefits and Costs of Federal Regulations and Unfunded Mandates on State, Local, and Tribal Entities 4, available at http://www.whitehouse.gov/omb/inforeg_regpol_reports_congress.

57 See Office of Management and Budget, n 63 above, 4-5. Compare this with the OECD's guidance on RA, which also refers to quality, efficiency, and social welfare functions. OECD, Building an Institutional Framework for Regulatory Impact Analysis - Guidance for Policymakers (2008) 7, 11, 14.

\footnotetext{
${ }^{58}$ Green Book, n 36 above, 8.

59 ibid 24 and Annex 5.
} 
including elements such as 'social, wellbeing and health inequalities', quality of life, impacts on human rights, and equality. ${ }^{60}$

\section{(B) Informational aspects and 'quality'}

RA regularly entails substantial data collection, consultations, analysis, and publications of various draft to final stage documents, which brings another potential function to the forefront. RA can serve as an informational and monitoring tool, both for regulators and interested stakeholders (subject, however, to the important limitations outlined in the next section). As such, RA can promote transparency and accountability and dialogue and control within the government as well as between the government and those affected by regulatory measures. ${ }^{61}$ Even if efficiency or social welfare cannot be effectively promoted by RA, its informational and related aspects would still constitute strong arguments in its favour. ${ }^{62}$ In this sense, RA can be understood as a control mechanism in a multi-layered principal-agent system, ${ }^{63}$ or, more subtly, as an 'information supply mechanism' that facilitates policy debates.

\footnotetext{
${ }^{60}$ BIS, n 39 above, 66-67.
}

${ }^{61}$ Ahdieh, n 45 above, 2019. Accountability relates to both the priorities that regulator pursue as well as the factors that are considered in designing policies. ibid 2021-2023.

${ }^{62}$ This idea is further explored below, see 000-000.

${ }^{63}$ See Radaelli \& de Francesco, n 1 above, 281-288. 
Informational aspects of RA are particularly emphasised in the European context. ${ }^{64} \mathrm{EU}$ impact assessments have been characterised as tools to enhance the amount and quality of information available to regulators and the public on the impacts of different policy options. ${ }^{65}$ According to the IA Guidelines, the EU impact assessment system

helps the EU institutions to design better policies and laws; facilitates betterinformed decision making throughout the legislative process; ensures early coordination within the Commission; takes into account input from a wide range of external stakeholders, in line with the Commission's policy of transparency and openness towards other institutions and the civil society; helps to ensure coherence of Commission policies and consistency with Treaty objectives ...; improves the quality of policy proposals by providing transparency on the benefits and costs of different policy alternatives and helping to keep EU intervention as simple and effective as possible; and helps to ensure that the principles of subsidiarity and proportionality are respected, and to explain why the action being proposed is necessary and appropriate. ${ }^{66}$

${ }^{64}$ Similar functions have been considered, albeit to a lesser degree, in the US. See, for example, Ahdieh, n 45 above, 2019-2022 on CBA's role in promoting transparency and agency monitoring. It should be kept in mind that the informational aspects are in tension with distortions and biases that afflict RA, on which see 000-000.

${ }^{65}$ See Alemanno \& Meuwese, n 16 above, 76-78; Meuwese, n 8 above, 41-49.

${ }^{66}$ IA Guidelines 2009, n 28 above, section 1.2. 
Thus, the drivers for RA in the EU have been said to be consultation, control and quality. ${ }^{67}$ The precise meaning of 'quality' in this context is unclear, although it seems to be based on the assumption that enhanced input into and transparency in policy decisions, combined with deeper quantitative analysis and emphasis on trade-offs, leads to better policies. ${ }^{68}$ While 'better' policies could also mean more efficient policies, efficiency functions are less pronounced in the EU. In part driven by the desire 'to avoid getting enmeshed in the American debate on the desirability of cost-benefit analysis as a tool for decision-making', the EU's impact assessment system is 'only in the second instance ... aimed at conditioning regulatory action to a positive cost-benefit balance' ${ }^{69}$ Indeed, the IA

${ }^{67}$ Alemanno \& Meuwese, n 16 above, 77, 89-91. Control, in this context, refers mainly to the desire to ensure that delegated powers in rulemaking, which are subject to reduced parliamentary control, are exercised in line with the limits and objectives of the power-conferring act. It can also extend, however, to control over regulators as exercised by the public.

${ }^{68}$ See ibid. Conversely, as Robert Baldwin has argued, the EU's 'better regulation' initiative, in which RA and improvements to the RA process play an important role, may not necessarily have the anticipated effect of improved or 'smarter' regulation due to limitations in which RA impacts regulatory processes. Baldwin, n 27 above, 501-507. Thus, Baldwin suggests among others to initiate RA as early as possible in the regulatory process and, additionally, to leverage review procedures to improve regulatory systems. ibid 507-511. In this latter regard, the present article's revised view of RA is broadly in line with these proposals. See $\mathrm{XXX}-\mathrm{XXX}$.

${ }^{69}$ Alemanno \& Meuwese, n 16 above, 78. Still, the IA Guidelines 2009 contain numerous references to 'efficiency', in particular in their guidance on comparing different policy options. 
Guidelines suggest the use of various methods and a mix of quantitative and qualitative analysis. $^{70}$

The EU's approach to RA is in part also reflected in the UK's approach. Until recently, the UK's impact assessment guidance stated that 'Impact Assessment is both a continuous process to help the policy-maker fully think through and understand the consequences of possible and actual Government interventions in the public, private and third sectors; and a tool to enable the Government to weigh and present the relevant evidence on the positive and negative effects of such interventions, including by reviewing the impact of policies after they have been implemented. ${ }^{, 71}$ The guidance also explains that the preparation and publication of assessments ensure that those with an interest understand and can challenge government intervention, the potential impact of new policies on them and estimated costs and benefits, and that they can identify unintended consequences. ${ }^{72}$ Similarly, the National Audit Office has defined the purpose of impact assessments as 'to inform all stages of the policy making process', that is from the initial steps to the final stages of monitoring and evaluation. ${ }^{73}$ The NAO has stated that 'all stakeholders of the regulations ... must see the [impact assessment] process as credible ${ }^{74}$ and suggested using a framework that identifies

\footnotetext{
${ }^{70}$ See IA Guidelines 2009, n 28 above, 45-47.

${ }^{71}$ HM Government, n 38 above, 3-4.

${ }^{72}$ ibid.

${ }^{73}$ National Audit Office, Evaluation of Regulatory Impact Assessments Compendium Report 200304 (London: The Stationary Office, 2004) 3; see also Baldwin, n 27 above, 491 (explaining the informational, decision-making function of impact assessments).

${ }^{74}$ National Audit Office, n 73 above, 3.
} 
a policy rationale and objectives, includes an appraisal of the likely impacts, and uses feedback gained from monitoring and evaluation feedback to inform future actions. ${ }^{75}$

Thus, while the EU and UK emphasise informational and procedural aspects of RA, positive and negative impacts - in other words, costs and benefits ${ }^{76}$ - are important. In particular, in practice the UK appears more cost-benefit driven in its impact assessments than the EU, and thus closer to the traditional US model. ${ }^{77}$ However, the role of RA, according to the official guidance documents, is primarily seen as focused on finding and presenting impacts and how they affect policy options, rather than a tool to enhance efficiency in a strict economic sense. Nevertheless, it is challenging to 'go against the numbers ${ }^{978}$ and regulators will find it difficult to justify policies that lack net benefits. ${ }^{79}$

\footnotetext{
${ }^{75}$ See ibid 10 and $16-39$.

76 The preferred term in the EU and UK is 'positive and negative impacts' instead of 'costs and benefits.' Nevertheless, ultimately, it is difficult to draw a clear line between the two concepts.

${ }^{77}$ See OECD, Sustainability in Impact Assessments - A Review of Impact Assessments in selected OECD countries and the European Commission (2012), available at http://www.oecd.org/gov/regulatory-policy/Sustainability\%20in\%20impact\%20assessment\%20SGSD(2011)6-FINAL.pdf, 24 (stating that '[t]he British IA process is clearly based on CBA').

${ }^{78}$ See generally, T.M. Porter, Trust in Numbers: The Pursuit of Objectivity in Science and Public Life (Princeton: Princeton University Press, 1995) (with a focus on CBA in chapter 7).

${ }^{79}$ A side effect of this may be that regulators increase estimates of benefits or, alternatively, put greater emphasis on non-monetised impacts to avoid quantification. Both effects can be observed in the case studies that will be discussed below.
} 


\section{(B) Bias-reduction and promotion}

Sunstein and others have emphasised RA's function as a tool to reduce cognitive biases in public assessments and on the part of regulators. Indeed, given its structured and systematic approach, it is very plausible that proper RA can mitigate false or distorted perceptions, such as about the magnitude and probability of certain risks and benefits. ${ }^{80}$ For instance, due to heuristics and biases, public opinion may favour regulation that has high costs and low benefits, or neglect to focus on costs and benefits that are not clearly visible. Examples for this are skewed perceptions of risks that stem from well-known, highly publicized diseases (such as cancer) or catastrophic events (such as nuclear accidents), which are perceived to be more probable than other, lesser known but more substantial risks. A thorough fact-based analysis that assesses a policy's potential costs and benefits may correct certain misperceptions in this regard.

Yet, the outcomes of RA can themselves be tainted by biases. Even worse, as a flipside of RA's informational function, there is a danger that the RA process can be consciously abused. Those that conduct RA may present and interpret information - or choose to supress information - in a manner that supports certain policies that are favoured by the government, although the actually or potentially available knowledge base would objectively allow for different conclusions that support different policy decisions. There may also be a shortage of information, which is especially likely in new areas, where

${ }^{80}$ See C. R. Sunstein, 'Cognition and Cost-Benefit Analysis' (2000) 29 Journal of Legal Studies 1059, arguing that CBA is most plausibly justified on cognitive grounds and providing examples; Ahdieh, n 51 above, 2012-2014, noting that this function can also be seen as relating to efficiency. 
available information may be thin or of poor quality. Indeed, rather than serving as a disciplining device, RA may become 'camouflage" ${ }^{\prime 81}$ or a 'ritual of verification' instead of advancing substantive goals. ${ }^{82}$ Thus, the fact that RA has been undertaken does by itself not necessarily mean that transparency has been increased. Given these limitations, coupled with RA's often complex technical and quantified elements, some commentators have argued that RA and its disclosures may in fact decrease transparency. ${ }^{83}$ Nevertheless, this latter conclusion is hardly convincing, given that even the disclosure of incorrect data (as used in RA) seems inherently more information enhancing compared to the lack of disclosure. With disclosure, third parties can at least examine and criticise the use of data.

To be sure, there are limits to the level of depth that RA can reasonably be expected to engage with the underlying data and available policy options. Yet, if the knowledge base that is or should be available can objectively be read to (also) support policies other than the ones preferred by the body conducting the analysis and this is not appropriately discussed as part of the RA process, the line between legitimate information and undesirable 'promotion' and misinformation may well be crossed. ${ }^{84}$

${ }^{81}$ See Coates, n 6 above, 898-902.

${ }^{82}$ See Radaelli \& de Francesco, n 1 above, 282. This point will also be discussed below, 000-000.

${ }^{83}$ For example, D. M. Driesen, 'Distributing the Costs of Environmental, Health, and Safety

Protection: The Feasibility Principle, Cost-Benefit Analysis, and Regulatory Reform' (2005) 32

Boston College Environmental Affairs Law Review 1, 78-80; Coates, n 6 above, 899. See also 000000 on the related issues of quantifiability and complexity, which impact RA's transparency enhancing fuction.

${ }^{84}$ See Posner \& Weyl, n 7 above, 249. 
Misinformation and promotion, in the negative sense, can be the result of unconscious biases, such as where regulators interpret information in light of pre-conceived opinions and distorted perceptions or, in the worst case, conscious decisions. It is acknowledged and will be discussed in more detail below - that RA contains 'a degree of political judgment. ${ }^{85}$ However, this judgment should as much as possible be limited to the decisions that are made based on RA, not the fact-gathering and analytical stages, although it may become necessary with respect to the latter. A potential way to mitigate this issue is through independent controls throughout various stages of the process and, in addition, by deeper and more critical analysis, as will also be further explored elsewhere in this article.

\section{(B) Regulatory pace}

Finally, an ancillary function of RA can consist of its impact on the pace of governmental intervention. RA may serve as a tool to strengthen existing regulation or identify and justify new areas suitable for regulation. In part, this relates to RA's promotional aspects since the government can use RA to advance its regulatory goals. Yet, RA is often thought to serve more as a brake on regulation than a driver. ${ }^{86}$ In this vein, cost-benefit analysis has been attacked with critics alleging that it unduly burdens regulation and supports a deregulatory

\footnotetext{
${ }^{85}$ Alemanno \& Meuwese, n 16 above, 78; 000-000 below.

${ }^{86}$ In the US in particular RA is often perceived as lending itself more to an anti-regulatory stance. See, for example, Ahdieh, n 51 above, 1987, 1986 ('[A] new weapon has emerged in the battle to delay, defer, or prevent the adoption of new financial rules: the claim of asserted inadequacies in the cost-benefit analysis of relevant regulations.'); Bishop \& Coffee, n 21 above, 571; Hahn \& Sunstein, n 12 above, 1505-1510; Driesen, n 9 above.
} 
agenda, sometimes coupled with the argument that RA overestimates costs while underestimating benefits. ${ }^{87}$ Thus, RA can slow down or block the regulatory process due to the required fact-finding and analysis, leading to longer and more costly decision-making. ${ }^{88}$

Whether RA's function as a 'break' on regulation is undesirable or desirable is a matter of perspective and depends on the specific circumstances. In any event, however, the actual effect of RA on the regulatory pace is not clear, with one author for instance noting that in the US context, there is 'little evidence that the requirement that agencies conduct

${ }^{87}$ See, for example, early critiques by E. M. Kennedy \& R. Nader, published as conference proceedings in T. B. Clark et al. (eds), Reforming Regulation (Washington et al: American Enterprise Institute for Public Policy Research, 1980) 21-28 and 76-80, respectively. More recent contributions voicing similar skepticism include L. Heinzerling, 'Quality Control: A Reply to Professor Sunstein' (2014) 102 California Law Review 1457; F. Ackerman \& L. Heinzerling, Priceless: On Knowing the Price of Everything and the Value of Nothing (New York: New Press, 2004); D. Kysar, Regulating from Nowhere: Environmental Law and the Search for Objectivity (Yale University Press: New Haven, 2010); R.L. Revesz \& M.A. Livermore, Retaking Rationality: How Cost-benefit Analysis Can Better Protect the Environment and Our Health (New York: OUP, 2008); T. O. McGarity, 'A Cost-Benefit State' (1998) 50 Administrative Law Review 7, 50 (1998); S. A. Shapiro \& R. L. Glicksman, Risk Regulation At Risk: Restoring A Pragmatic Approach (Berkeley: Stanford University Press, 2003). See also Radaelli \& de Francesco, n 1 above, 288, citing empirical studies to this effect.

${ }^{88}$ See Ahdieh, n 45 above, 2016-2017, 1993 (stating that CBA 'may foster efficient ends or be paralyzing'); Alemanno \& Meuwese, n 16 above, 80, noting the potential inefficiencies that impact analyses may cause in the EU rulemaking context. 
cost-benefit analyses of significant regulatory efforts has deterred rulemaking'. ${ }^{89}$ Indeed, RA may also have the opposite effect and facilitate regulatory actions, ${ }^{90}$ as will be shown in the following examples referring to the UK and EU. Indeed, as these cases will also reveal, corporate law can be partially driven by overestimation of regulatory benefits, which stands in stark contrast to concerns voiced for instance in connection with environmental RA. Nevertheless, a 'slow down' effect of RA is supported insofar as RA requirements can make it easier for courts ${ }^{91}$ and governmental bodies to curtail regulatory initiatives. ${ }^{92}$ This will be seen in the case of the SEC's proxy access rule discussed below.

${ }^{89}$ Stuart Shapiro, 'Unequal Partners: Cost-Benefit Analysis and Executive Review of Regulations' (2005) 35 Environmental Law Review 10433, 10436.

${ }^{90}$ Radaelli \& de Francesco, n 1 above, 281.

${ }^{91}$ A recent example of judicial review - rejecting a new SEC rule - based on RA is the Business Roundtable case, which will be discussed in the following part. In the EU, RA has also played a role, albeit a smaller one, in the context of judicial proportionality review of regulations and directives. See Alemanno \& Meuwese, n 16 above, 90; A. Alemanno, 'A Meeting of Minds on Impact Assessment: When Ex Ante Evaluation Meets Ex Post Judicial Control', (2011) 17 European Public Law 201. Impact assessments have been considered in this context in decisions including case C-58/08, Vodafone Ltd et al v Secretary of State for Business, Enterprise and Regulatory Reform (2010) ECR I-4999 and case C- 176/09, Luxembourg v European Parliament et al (2011) ECR I-0000 (both upholding the provisions in question).

${ }^{92}$ As Eric Posner has noted, RA may serve a political function by restraining rulemaking indirectly through reporting requirements that facilitate political and judicial checks. E. A. Posner, 'Cost- 


\section{(A) EXAMPLES}

Having explored RA generally, this part now turns to practical applications in the corporate law field. Three examples will be used to illustrate RA in this context: The United States Securities and Exchange Commission's (SEC) proxy access rule; the UK's most recent executive remuneration reforms; and the EU's new regime governing disclosure of nonfinancial corporate information.

While the following case studies will be largely descriptive in nature, they will illustrate the difficulties in quantifying costs and benefits as well as the tendency for RA to overcome potential negative cost-benefit ratios by relying heavily on unquantifiable or non-monetised benefits, which tend to be regarded as more substantial than (monetised or non-monetised) costs. The case studies will also highlight problems with RA evidence bases, either in the form of a dearth in sources and engagement, including selective use of evidence, or, alternatively, strong engagement and broad use of sources but inconclusive evidence.

\section{(B) Proxy access}

US financial regulatory agencies are generally not legally required to conduct conventional RA, although they may do so on a voluntary basis. ${ }^{93}$ They are, however, normally mandated to take into account a variety of factors and the 'impact' of regulatory

Benefit Analysis as a Solution to a Principal-Agent Problem' (2011) 53 Administrative Law Review 289, 289 n 3, 296.

${ }^{93}$ The executive orders requiring CBA do not cover 'independent regulatory agencies,' a category that includes most federal financial regulators. Pierce, n 14 above, 573. 
measures. ${ }^{94}$ As a prominent example, the SEC is required by statute to 'also consider, in addition to the protection of investors, whether the action will promote efficiency, competition, and capital formation. ${ }^{95}$ Traditionally, based on this requirement, the SEC conducts in-depth CBA of its proposed rules. In addition, the SEC - like other financial regulatory agencies - is subject to the general rule-making requirements of the Administrative Procedure Act (APA), which allows reviewing courts to set aside rules that are 'arbitrary, capricious, an abuse of discretion, or otherwise not in accordance with law. ${ }^{96}$ Depending on how this language is interpreted, the APA may serve as a basis to invalidate agency actions in case of improper use of or failure to use CBA. ${ }^{97}$

Despite the lack of a firm mandate for financial regulators to undertake formal CBA, the issue of RA in financial regulation has been highlighted in recent court decisions. Of particular interest for this article is Business Roundtable v. SEC, ${ }^{98}$ which relates to the composition of corporate boards and thus touches upon a core area of corporate governance. The underlying issue in this case was a novel SEC rule that would have required public companies to provide shareholders with information about, and their ability to vote for, shareholder-nominated candidates for the board of directors.

${ }^{94}$ See ibid $578-610$.

${ }^{95}$ See $\S 3$ (f) of the 1934 Securities Exchange Act, 15 U.S.C. $\S 78 c(f) ; \S 2(b)$ of the Securities Act of 1933, 15 U.S.C. $§ 77 b(b) ; ~ § ~ 2(c)$ of the Investment Company Act of 1940, 15 U.S.C. $\S 80 a-2(c)$. For a detailed discussion, see Ahdieh, n 45 above, 1999-2004.

${ }^{96} 5$ U.S.C. $\S \S 551-59$.

${ }^{97}$ Pierce, n 14 above, 575.

${ }^{98} 647$ F.3d 1144 (D.C. Cir. 2011). 
This rule, Rule 14a-11, allowed qualified shareholders to nominate persons for election to the board and to ask their company to include these nominees, along with supporting statements, in its proxy materials and proxy voting card. ${ }^{99}$ Thus, shareholders wishing to nominate candidates other than those nominated by the incumbent directors would have been partially freed from the onerous costs of seeking to affect changes in the board's composition by staging a 'proxy contest'. ${ }^{100}$ As such, the rule represented a significant change to the existing board governance framework, with the potential to have a substantial effect on the balance of power between shareholders and boards.

The SEC's final release accompanying Rule 14a-11 contained its CBA of the new provisions. ${ }^{101}$ Beginning with a consideration of the rule's expected benefits, the analysis discussed among others improvements to shareholders' ability to exercise their state law

9975 Fed. Reg. 56,668, 56,670 (2010). Additionally, the SEC sought to amend Rule 14a-8 in order to allow shareholders to propose proxy nomination procedures for their companies. Although, as will be discussed below, these regulatory changes were not implemented, some companies have now voluntarily adopted 'proxy access'. See Financial Times, 'Proxy access is no cure for US governance' (17 January 2016), available at http://www.ft.com/cms/s/0/4b9eb89a-bba2-11e5-b1518e15c9a029fb.html.

${ }^{100}$ In a proxy contest, shareholders nominate outsiders and solicit votes for them to be elected to the company's board. This process is costly because dissidents have to prepare and pay for their own proxy statements (which contain information for shareholders), with estimated price ranges between $\$ 30,000$ to $\$ 9$ million per contest. See M. Kahan \& E. B. Rock, 'The Insignificance of Proxy Access’ (2011) 97 Virginia Law Review 1347, 1384; Schedule 14A, 17 CFR § 240.14a-101 (2010). 10175 Fed. Reg. 56,668, 56,753-56,771 (2010). 
rights to nominate and elect directors; the introduction of minimum uniform procedures for inclusion of shareholder director nominations and enhanced ability for shareholders to adopt director nomination procedures; more informed voting decisions in director elections due to improved disclosure of shareholder director nominations and enhanced shareholder communications; and the potential for improved board performance and company performance. Nevertheless, in terms of quantifiable benefits, the CBA only included savings relating to printing and mailing costs, which were estimated to amount to an average of $\$ 18,000$ per shareholder. However, while acknowledging that certain quantifiable benefits may be less than the quantifiable costs of the new rules, the SEC pointed to benefits of the new rules that were not easily quantifiable (including greater shareholder participation and communication in the director nomination process) and stated that it believed 'that these benefits, collectively, justify the costs of the new rules.' 102

On the other side of the equation, the SEC considered costs related to potential adverse effects on company and board performance; costs related to additional complexity of the proxy process; costs related to preparing disclosure, printing and mailing, and additional solicitations against the election of shareholders' director nominees and shareholder proposals. Insofar as the CBA quantified these costs (including those connected to related amendments to Rule $14 \mathrm{a}-8$ on shareholder proposals), the estimates amounted approximately to a combined yearly cost for companies of up to 16,000 hours of personnel time and an additional $\$ 9.5$ million per year for external services and other expenses, with an additional cost for solicitation, which one commentator estimated to be up to $\$ 14$

\footnotetext{
102 ibid 56,775.
} 
million. For shareholders, quantified costs were estimated at approximately 8,000 hours in personnel time and \$1 million for outside services per year. In a separate section, the SEC also discussed the potential burden on competition and considered the rule's effects on promotion of efficiency, competition, and capital formation. This section confirmed the Commission's view that the benefits justified the costs and that the rule was efficient. ${ }^{103}$

Overall, the CBA considered and engaged in considerable detail with academic literature, empirical studies, and numerous comments received from stakeholders and commentators. ${ }^{104}$ On the cost side, a particularly contentious point was the amount that company boards would need to spend on solicitation and campaign costs as a result of the rule. However, the SEC did not attempt to quantify this cost, noting that Rule $14 \mathrm{a}-8$ did not require such actions. On the benefits side, the SEC's argument that facilitating shareholders' rights in directorial elections may have the potential of improving board accountability and efficiency and increasing shareholder value was of particular interest. The SEC acknowledged that there was a sharp divide among commenters and that available

${ }^{103}$ ibid 56,771-56,776.

104 Together, the CBA and the 'Consideration of Burden on Competition and Promotion of Efficiency, Competition and Capital Formation' were discussed over almost 30,000 words (including extensive textual footnotes), which is roughly three times more than the sections on costs and benefits in the UK's two executive remuneration impact assessments combined. See also David Zaring, 'The State of Cost-Benefit Analysis at the S.E.C.' (DealBook, New York Times, 13 July 2015), available at www.nytimes.com/2015/07/14/business/dealbook/the-state-of-cost-benefitanalysis-at-the-sec.html, noting that the proxy access rule devoted 17 percent and the conflict minerals rule 21 percent of their final versions to economic analysis. 
empirical data 'may appear mixed'. ${ }^{105}$ It also stated that it had carefully considered the data and critical comments that suggested the opposite of what the SEC expected, namely the 'potential for negative effects due to management distraction and discord on the board.' 106

Nevertheless, the SEC, placing considerable weight on a study showing a positive effect on shareholder value of so-called 'hybrid boards', ${ }^{107}$ concluded that 'the totality of the evidence and economic theory' supported the view that facilitating shareholders' proxy access 'has the potential of creating the benefit of improved board performance and enhanced shareholder value,' either through actual election of shareholder-nominated directors or due to companies' greater reception to shareholders' concerns. Thus, the SEC ultimately found that the potential benefits of improved board and company performance and shareholder value justified the new regime's potential costs. ${ }^{108}$

Shortly after Rule 14a-11 took effect, the Business Roundtable, an organisation that promotes US business interests, and the Chamber of Commerce challenged the rule, which meant that the D.C. Circuit was entrusted with deciding the further fate of $14 a-11 .^{109}$ The court's opinion was short and damaging. According to the court, the SEC 'inconsistently and opportunistically framed the costs and benefits of the rule; failed adequately to quantify the certain costs or to explain why those costs could not be quantified; neglected to support its predictive judgments; contradicted itself; and failed to respond to substantial problems 10575 Fed. Reg. 56,668, 56,761 (2010).

106 ibid.

${ }^{107}$ Referring to boards composed of a majority of incumbent and a minority of dissident directors. 10875 Fed. Reg. 56,668, 56,761 (2010).

${ }^{109}$ Responding to a request for an injunction, the court initially stayed the rule pending its review. 
raised by commenters. ${ }^{110}$ In commenting specifically on the SEC's treatment of the indirect, and more difficult to assess, systemic effects of facilitated proxy access and potentially increased number of dissident board members, the court opined that the SEC relied upon insufficient empirical data in measuring the rule's benefits, namely improved board performance and increased shareholder value. ${ }^{111}$ In finding that reliance on merely 'mixed' empirical evidence was insufficient to support the new rule, ${ }^{112}$ the court imposed a

${ }^{110}$ Business Roundtable, n 98 above, at 1148-1149. See, however, ICI v. CFTC, 720 F.3d 370 (D.C. Cir. 2013), where the same court granted greater deference to regulatory CBA in the context of a rule promulgated by the US Commodity Futures Trading Commission.

${ }^{111}$ But see the critique in G. M. Hayden \& M. T. Bodie, 'The Bizarre Law and Economics of Business Roundtable v. SEC' (2012) 38 Journal of Corporation Law 101, 102, arguing that the court's own reasoning 'rests on flawed empirical and theoretical conclusions about proxy access and corporate governance'. See also J. E. Fish, 'The Long Road Back: Business Roundtable and the Future of SEC Rulemaking' (2013) 36 Seattle University Law Review 695, 701 (opining that the court substituted its own policy judgment for that of the SEC); Ahdieh, n 45 above, 2064 (criticising the court's lack of deference). Conversely, E. A. Posner \& G. W. Weyl, 'Benefit-Cost Paradigms in Financial Regulation' (2014) Journal of Legal Studies S1, S9, conclude that 'the SEC did not monetize the expected benefits and costs of the rule, and therefore had no basis for claiming that the rule complied with a benefit-cost analysis, and hence served the public interest.'

${ }^{112}$ Business Roundtable, n 98 above, at 1150-1151. For more details on the empirical evidence considered by the SEC and its role in the decision, see B. Kraus \& C. Raso, 'Rational Boundaries for SEC Cost-Benefit Analysis' (2013) 30 Yale Journal on Regulation 289, 312-314 (noting, among others, that the court mistook a report that had been paid for by the Business Roundtable as an independent empirical study) and Hayden \& Bodie, n 111 above, 120-125. 
high evidentiary burden on the SEC with respect to its CBA, which - along with the court's overall decision - was subsequently criticised in academic commentary. ${ }^{113}$ Finally, using the APA's 'arbitrary and capricious' standard, the D.C. Circuit vacated Rule 14a-11, concluding that the SEC neglected its statutory obligations to properly quantify and assess economic consequences of the rule. ${ }^{114}$

\section{(B) Executive remuneration}

RA also played an important role in the UK government's latest reform of executive remuneration. In main part, these reforms consisted of the introduction of mandatory say on pay and heightened disclosure requirements. ${ }^{115}$ The background to the new regime was the long-standing political discontent with executive pay, public and media pressures, and the

${ }^{113}$ A standard close to requiring 'clear and convincing' evidence, as some authors have suggested. Kraus \& Raso, n 112 above, 361; Hayden \& Bodie, n 111 above, 108 n 55 (citing various academics that have expressed concern over the Business Roundtable decision). See also n 161 and accompanying text below, suggesting that the SEC's regulatory analysis should have passed judicial scrutiny under the applicable standard.

${ }^{114}$ Subsequently, the SEC has issued a guidance memorandum, addressing many of the criticisms put forth in the Business Roundtable decision. SEC, 'Memorandum - Current Guidance on Economic Analysis in SEC Rulemaking' (2012), available at https://www.sec.gov/divisions/riskfin/rsfi_guidance_econ_analy_secrulemaking.pdf.

115 The new framework, which applies to UK incorporated quoted companies, became effective on October 1, 2013. For an overview, see M. Petrin, 'Executive Compensation in the United Kingdom - Past, Present, and Future' (2015) 36 The Company Lawyer 195. 
recent financial crisis, which once again put a spotlight on executive pay and its relation to risk-taking and performance. Broadly speaking, the government's position in the process leading up to the reform measures was that there was a 'disconnect between pay and performance' and unstainable 'ratcheting-up of executive pay.' 116

With the new regime, the government's stated aim was improving the link between pay and performance; reducing rewards for failure; promoting engagement between companies and shareholders; and empowering shareholders to hold companies accountable. ${ }^{117}$ To this end, a two-tiered approach was introduced ${ }^{118}$ and adopted in late $2013 .{ }^{119}$ First, at least

${ }^{116}$ BIS, 'Directors' Pay: Consultation on revised remuneration reporting regulations' (June 2012) 5. For further background, see ibid 9-14; Petrin, n 115 above.

${ }^{117}$ BIS, n 116 above, 5.

118 See, generally, The Large and Medium-sized Companies and Groups (Accounts and Reports) Amendment Regulations 2013 ('2013 Regulations'), revoking and replacing Schedule 8 of the Companies and Groups (Accounts and Reports) Regulations 2008; Enterprise and Regulatory Reform Act 2013, amending the Companies Act 2006.

119 The EU has proposed executive remuneration rules (in addition to separately proposed rules applicable to financial institutions) that are similar to the UK model. An impact assessment has already concluded that the positive impacts would clearly outweigh costs and burdens. See European Commission, 'Impact Assessment, accompanying the document Proposal for a Directive of the European Parliament and of the Council on amending Directive 2007/36/EC as regards the encouragement of long-term shareholder engagement and Directive 2013/34/EU as regards certain elements of the corporate governance statement and Commission Recommendation on the quality of corporate governance reporting ('comply or explain')' (9 April 2014), SWD(2014) 127 final. 
once every three years, companies are required to hold a binding shareholder vote on their general policy for annual directorial remuneration. Second, shareholders get an annual nonbinding advisory vote regarding the ongoing implementation of remuneration policies. Additionally, executive remuneration is subject to greater disclosure requirements and there are new civil consequences for individuals who authorise and receive unapproved payments.

The Department for Business, Innovation \& Skills conducted two impact assessments to accompany the new provisions, one on shareholder voting and one on the transparency portions of the new provisions. In the assessment of shareholder voting on executive remuneration, the government presented executive pay as a problem of market failure and agency costs. ${ }^{120}$ It also restated its aims and emphasised shareholder empowerment as the key to address executive remuneration issues:

The policy objective is to address failures in the governance of directors' pay by equipping shareholders with the enhanced tools they need to challenge companies. Shareholder empowerment lies at the heart of the UK's corporate governance framework and these reforms are consistent with that approach. They will enable shareholders to promote a stronger, clearer link between pay and performance and to challenge companies on rewards for mediocrity or failure, while still allowing for exceptional performance to be rewarded. ${ }^{121}$

This impact assessment did not attempt to monetise costs, benefits, or net benefits, citing difficulties in predicting behavioural changes in shareholders and companies as well

\footnotetext{
${ }^{120}$ BIS, 'Shareholder votes on directors' remuneration - Impact Assessment' (9 May 2012) 1, 4. ${ }^{121}$ ibid 1.
} 
as uncertainties regarding the development of the wider economy and regulatory environment. ${ }^{122}$ Referring to key non-monetised costs, the impact assessment stated that there may be 'some' costs in relation to increased shareholder engagement and time spent on updating pay policies. ${ }^{123}$ It also noted potential costs related to holding an additional general meeting to vote on revised pay proposals, 'but consultation responses indicate that companies will take action to avoid such an outcome'. ${ }^{124}$

In terms of key benefits, the impact assessment found potentially 'significant' benefits to business and shareholders as a result of better alignment between pay schemes and performance, which, however, it said were difficult to monetise. ${ }^{125}$ Key non-monetised benefits were identified as reduced engagement costs due to improved shareholdercompany collaboration, increased long-term performance through better pay design, more efficient resource allocation by increased dividend payouts or reinvestment, and improved corporate governance with lower cost of capital. ${ }^{126}$ After weighing unmonetised benefits against unmonetised costs, the impact assessment concluded that the preferred option was likely to result in benefits 'significantly larger than any potential increase in costs that companies might face or loss of earnings faced by individual directors'. ${ }^{127}$

122 ibid 2, 20.

${ }^{123}$ ibid 2 (summarising the assessment's results).

124 ibid.

125 ibid.

126 ibid.

${ }^{127}$ ibid 20-30, providing a narrative analysis of the policy options under considerations. 
The separate impact assessment on the effects of increased transparency of executive remuneration reporting estimated that the proposed reforms would have a negative net benefit over 10 years of $£ 51.2$ million and yearly net costs to businesses of $£ 5.2$ million. ${ }^{128}$ Costs in this regard, characterised as 'transitional one-time costs', consisted of internal compliance and external professional fees, while the benefits were reduced monitoring costs by shareholders and non-executive directors. Yet, the impact assessment's recommendation in support of increased disclosure rested heavily on 'key non-monetised benefits'. These were described to include the potential for more efficient allocation of resources and improved managerial incentives, more informed and efficient shareholdercompany engagement, and - ultimately - 'a more engaged and empowered shareholder base' that 'could lead to better corporate governance in UK companies which is associated with lower costs of capital'. ${ }^{129}$

Based on these benefits, the impact assessment on transparency of executive remuneration reporting concluded that the transitional costs for companies 'are likely to be significantly outweighed by the potential improvements in company performance that can result from better aligned executive remuneration due to better information'. This conclusion was further underlined by a break-even type argument, with the assessment noting that 'for the FTSE100 alone, the market capitalisation would need to increase annually by only 0.0003 per cent, or operating profit by only 0.003 per cent to exceed the

\footnotetext{
${ }^{128}$ BIS, 'Improved Transparency of Executive Remuneration - Impact Assessment' (29 May 2013) 1, 3 (summarising the assessment's results).

${ }^{129}$ ibid 3.
} 
costs. ${ }^{, 130}$ Overall, while the quantified costs and benefits resulted in negative benefits, the non-monetised benefits were thought to be so large as to lead to a positive overall outcome.

\section{(B) Non-financial disclosure}

Another example of the application of RA in the corporate realm is provided in the area of non-financial disclosures, which touches upon corporate social responsibility (CSR) and from a broader corporate law perspective - the discussion surrounding the corporate purpose and companies' role in our society. While other jurisdictions have introduced comparable measures, ${ }^{131}$ this section focuses on the EU's recently adopted requirements regarding corporate disclosure of non-financial and diversity information.

As per a 2014 directive, companies and groups exceeding an average of 500 employees during a financial year, as well as parent companies of qualifying entities, shall disclose information on three areas related to corporate social responsibility: Policies, risks and outcomes pertaining to environmental matters; social and employee-related aspects; and respect for human rights, anti-corruption and bribery issues. ${ }^{132}$ The disclosed information

\section{0 ibid 5.}

${ }^{131}$ Examples of social disclosure can be found in the UK, among other jurisdictions. Furthermore, in the US, a noteworthy recent SEC rule imposed a requirement on corporations to disclose information on conflict minerals. See section 1502 of the Dodd-Frank Act, amending the Securities Exchange Act of 1934 by inserting Section 13(p).

${ }^{132}$ Directive 2014/95/EU of the European Parliament and of the Council of 22 October 2014 amending Directive 2013/34/EU as regards disclosure of non-financial and diversity information by 
should include a description of the company's business model; a description of the contents and outcome of the policies the company pursues in relation to the subject matter of the disclosures, including implemented due diligence processes; the principal risks related to those matters; and non-financial key performance indicators that are relevant to the particular business, insofar as they relate to these specific areas. ${ }^{133}$ Companies can disclose either through a non-financial statement in the annual report or - on a voluntary basis - a separate, more detailed report. Where such a stand-alone report is submitted, the company is exempt from the requirement to also include a statement in its annual report.

In terms of the Directive's non-financial disclosure requirements other than pertaining to diversity, which will be used as an example herein, the overall goal is to increase the quality and quantity of CSR-related information, in line with the EU's previously stated goal of strengthening corporate social responsibility. ${ }^{134}$ The impact assessment of the new provisions $^{135}$ reiterated this focus on CSR. Its analysis and support of regulatory

certain large undertakings and groups. In addition, companies are required to disclose information on policies in relation to diversity, broadly defined, pertaining to their administrative, management, and supervisory bodies (hereinafter the 'Directive'). This article, however, focuses on the CSR portion of the Directive.

${ }^{133}$ ibid articles 1 and 3, amending Directive 2013/34/EU by inserting articles 19a and 29a.

${ }^{134}$ As recently reiterated in EU Commission, 'The EU's 2011-2014 Strategy for Corporate Social Responsibility' (25 October 2011) COM(2011) 681 final.

${ }^{135}$ EU Commission, 'Impact Assessment Accompanying the document Proposal for a Directive of the European Parliament and of the Council amending Council Directives 78/660/EEC and 
intervention requiring disclosure of non-financial information was based on three main considerations: societal and investors' demand for transparency and accountability; the connection between non-financial and financial performance; and capital market efficiency. The problem, according to the assessment, is inadequate transparency of non-financial information, both in terms of quality and quantity, acerbated by lack of regulation and a market failure caused by a lack of incentives and uncertain benefits attached to such disclosure. ${ }^{136}$ To mitigate these ills, the impact assessment identified as the preferred policy option the mix of mandatory and voluntary disclosure measures discussed above and later adopted by the Directive. ${ }^{137}$

The assessment identified annual compliance cost, stemming from drafting reports, publication, or staff training, in the range of $€ 600-4300$ per year per company, resulting in an overall cost of $€ 10.5$ to 75.25 million. For companies that choose to comply with the voluntary portion of the new disclosure regime, the cost of producing a separate report was estimated to be in the range of $€ 33,000$ to $€ 604,000 .{ }^{138}$ However, although it seems likely that some companies will face pressures to produce more detailed voluntary reports - and,

83/349/EEC as regards disclosure of nonfinancial and diversity information by certain large companies and groups' (16 April 2013) SWD(2013) 127 final.

136 ibid 10-12.

${ }^{137}$ ibid 24-30.

138 ibid 40. 
indeed, that these reports could have a greater impact - the assessment did not include expenses incurred in compiling these reports in the preferred policy option's analysis. ${ }^{139}$

As to the new disclosure regime's benefits, the assessment pointed to numerous improvements that were thought to be significant. These included increased transparency, which was expected to result in better performance of companies ${ }^{140}$ and better risk assessment as evidenced by 'a growing body of academic research [that] indicates a positive correlation between better non-financial and financial performance'; ${ }^{141}$ increased accountability, reputation, and consumer trust, leading also to potentially increased demand; enhanced efficiency of capital markets through lower cost of capital due to better CSR and environmental, social and governance (ESG) factors; positive environmental impacts; a reduction in instances of companies' involvement in human rights abuses; positive effects on various fundamental rights; and a decrease in corporate short-termism. ${ }^{142}$

Nevertheless, the assessment also noted that the benefits flowing from non-financial disclosure were in most cases difficult to quantify, depended on the behaviour of specific companies and their managers and investors, and precise estimates as to what extent the preferred option would contribute to their achievement could not be provided. ${ }^{143}$ Indeed, in

${ }^{139}$ ibid 69.

140 The assessment draws a connection between the lack of disclosure and firms' financial performance, suggesting that increased disclosure will have a positive effect by causing companies to better integrate non-financial risks and opportunities into their operations and strategies. ibid 12.

${ }^{141}$ ibid 18 (emphasis omitted).

142 ibid 18, 37-42.

${ }^{143}$ ibid 28, 37, 39. 
an external study commissioned to support the impact assessment process, a sample of EU companies were asked whether they had sought to quantify the benefits from non-financial reporting. Out of the twenty companies that responded to this question, only three companies had tried to do so, and of these only one had arrived at a financial estimate. This company, which had a non-financial reporting cost in the range of $€ 300,000$, apparently identified efficiency savings of $€ 80$ million. Nevertheless, the details behind this impressive figure were not revealed and, as the external study noted, the company in question 'was unclear of the extent to which other factors than non-financial reporting were relevant. ${ }^{, 144}$

Thus, the impact assessment did not include any quantified estimates as to the benefits envisaged by mandatory non-financial disclosure. It also did not directly address the question of whether the benefits outweigh the costs, apart from one passage where the assessment pointed to consultations with users of non-financial information - in particular investors and NGOs - who 'suggested that the costs of reporting would be outweighed by the benefits to civil society, investors, in terms of increased transparency and possibility to take better account of companies' performance in the long term'. ${ }^{145}$ Still, as evidenced by the impact assessment's discussion of costs and benefits and its recommendation to adopt the preferred policy option that was later implemented by the Directive, it is clear that the unquantified benefits were thought to be highly significant, and larger than the costs. ${ }^{146}$

\footnotetext{
144 The Centre for Strategy and Evaluation Services (CSES), 'Disclosure of non-financial information by Companies' (December 2011) 31.

${ }^{145}$ EU Commission, above n 135, 45.

${ }^{146}$ See ibid, in particular 37-42.
} 


\section{(A) RECONCEPTUALiSING REgulatory ANALYSIS}

Drawing from the previous examples, and against the background of the functions that RA is theoretically thought to serve, the following sections further analyse the application of RA to corporate law, focusing on key difficulties. This part will conclude with outlining a revised view, suggesting that RA in corporate law should be mainly a procedural tool that enhances information, transparency, and monitoring, without recourse to specific normative criteria (such as efficiency). From a normative perspective, the revised view suggests that RA needs to rely on both quantified analysis and regulatory judgment, and that the focus for future improvements should be on improvements in consultation processes, critical analysis and engagement, ex post reviews, and transparency.

\section{(B) Complexity and quantifiability}

The most serious challenges faced by RA are likely those that relate to predicting and monetising future events or 'impacts' caused by new (or changing) policies. RA may give a false sense of certainty and precision when it assesses costs and benefits - or positive and negative impacts - that are difficult or even impossible to foresee, and even more difficult to quantify. In particular, issues may arise because regulatory changes can have complex consequences, due to a lack of reliable data, and based on problems related to assigning monetary values to impacts under these circumstances. In other words, difficulties in predicting how future systems will work under proposed new rules make it difficult to assess and quantify their impacts. Indeed, as John Coates has recently suggested, RA may 
often become an exercise in 'guesstimation' ${ }^{147}$ These weaknesses also negatively affect RA's informational functions given that analyses that are based on inaccurate numbers and assumptions might be read as objective facts by the public. The result are potentially misleading RA with severly reduced informational and transparency-enhancing benefits.

To be sure, these issues are known and it has been acknowledged that RA contains speculative elements and is susceptible to manipulation. ${ }^{148}$ Indeed, the UK's National Audit Office has pointed to weaknesses in reliability, including a lack of consideration of unintended consequences and failure to properly monetise costs and benefits, as a main concern for UK impact assessments, while an OECD review has cited studies criticising the UK's consideration of only a narrow range of impacts. ${ }^{149}$ It is not uncommon for regulators themselves to state expressly the limitations they face in conducting RA, which is also reflected in the case studies discussed above. Speaking more generally, the US Office of Management and Budget has also emphasised the difficulties in quantifying or monetising costs and benefits, warning that '[i]n some cases, quantification of various effects is highly speculative' and that 'significantly, prospective estimates may contain erroneous assumptions, producing inaccurate predictions. ${ }^{150}$

${ }^{147}$ Coates, n 6 above, 882, 998.

${ }^{148}$ See, for example, Ahdieh, n 45 above, 2011 (commenting on CBA).

${ }^{149}$ National Audit Office, Assessing the Impact of Proposed New Policies (London: The Stationary Office, 2010) 23; OECD, n 77 above, 25.

${ }^{150}$ Office of Management and Budget, n 56 above, 4. 
Yet, even with regulators acknowledging limitations, once a regulatory analysis has been completed, its outcome-determinative force is considerable. What counts in the end is that a final conclusion backs a certain policy, while any mention of limitations or uncertainties may be easily overlooked or become less important in the legislative or regulatory process. However, if the assumptions and numerical projections underlying the conclusion are not reliable, RA becomes problematic. Even for the UK and EU, where strict $\mathrm{CBA}$ and quantified numbers tend to be less important, strong reliance on nonmonetised impacts whose basis is not made sufficiently clear is difficult to reconcile with goals such as 'providing information and transparency on the benefits and costs of different policy alternatives' ${ }^{151}$ and, indeed, producing 'better' laws and regulations.

In connection with financial regulation, the usefulness of RA has recently been the subject of intense academic debate, with questions of uncertainty and quantifiability lying at the centre of the controversy. ${ }^{152}$ For instance, Jeffrey Gordon has argued that applying

${ }^{151}$ IA Guidelines 2009, n 28 above, section 1.2.

${ }^{152}$ Scholars questioning or denying the usefulness of CBA in financial regulation include Ahdieh, n 45 above; Fish, n 111 above, 713; Gordon, n 22 above; Ben-Shahar \& Schneider, n 11 above. Supporters of CBA include Posner \& Weyl, n 111 above; Rose \& Walker, n 18 above; E. Sherwin, 'The Cost-Benefit Analysis of Financial Regulation: Lessons from the SEC's Stalled Mutual Fund Reform Effort' (2006) 12 Stanford Journal of Law, Business \& Finance 1; C.R. Sunstein, 'Financial Regulation and Cost-Benefit Analysis' (2015) 124 Yale Law Journal Forum 263, available at http://www.yalelawjournal.org/pdf/SunsteinPDF_4nf1d4ar.pdf. An intermediate position is taken by Coates, $n$ above. 
CBA to complex issues of financial regulation is useless or even counterproductive. ${ }^{153}$ Gordon's main point is that CBA is incompatible with 'non-natural,' man-made systems such as the financial sector since the costs and benefits such systems produce depend on regulatory changes. He argues that financial regulation as 'a system constructed by the pattern of financial regulation itself and by the subsequent processes of adaptation and regulatory arbitrage' is not an area suitable for meaningful applications of CBA in determining its optimal setting. ${ }^{154}$ This unstable system, Gordon concludes, is not based on weighing of costs and benefits but rather a 'series of trade-offs of values that are normatively derived' ${ }^{155}$ On this basis, he also rejects the outcome in Business Roundtable ${ }^{156}$ arguing that the proxy access rule defies ready economic quantification because of its potential to modify the prevailing corporate governance paradigm. ${ }^{157}$

In corporate law, there are similar concerns. Regulating corporate governance is not comparable to imposing regulations such as those that relate to requirements to wear seatbelts, or dosages of drugs, or permitted emission levels of certain substances. Instead,

\footnotetext{
${ }^{153}$ Gordon, n 22 above.
}

${ }^{154}$ ibid, 351, 352-355. Compare, however, R. L. Revesz \& M. A. Livermore, Retaking Rationality: How Cost-Benefit Analysis Can Better Protect the Environment and our Health (New York: OUP, 2008) 14, arguing that CBA can be particularly useful in addressing uncertainty.

${ }^{155}$ Gordon, n 22 above, 353. Gordon contrasts this with regulatory frameworks in the health, safety, or environmental area that are based on exogenous anchoring principles of chemistry, biology, or physics, where he argues the use of CBA tends to be more appropriate.

${ }^{156}$ Above $n 98$.

${ }^{157}$ Gordon, n 22 above, 370-371. 
corporate law is another example of a 'man made' system that is not subject to the laws of chemistry, biology, and physics ${ }^{158}$ and generally not conducive to technical, science-based assessments. ${ }^{159}$ Rather, legislators and regulators design and implement the rules, and when they are changed, it becomes hard to foresee the consequences. ${ }^{160}$

To begin, extrapolating from these examples, regulators may believe that costs of reform measures are moderate (and can be estimated) while, at the same time, assuming that there are substantial benefits, which however cannot be quantified or, where they have been quantified, are subject to considerable limitations. In all three case studies - proxy access, executive remuneration, and non-financial disclosure - key benefits were not monetised, although it was these benefits that the analyses relied on most heavily to show that the balance of costs/benefits or impacts supported the proposed measures. As will be noted below, a lack of quantification is not by itself objectionable as long as it is justified and accompanied by a thorough qualitative analysis and explanation. In this respect, the court in Business Roundtable v. SEC went too far in faulting the SEC for what appeared to be a thorough and balanced CBA. ${ }^{161}$ The agency considered and engaged in detail with

158 ibid, 359.

${ }^{159}$ This is, for example, in contrast to environmental assessments. See M. Lee, EU Environmental Law, Governance and Decision-Making (Oxford: Hart Publishing, 2nd ed, 2014) 164-174.

${ }^{160}$ For this reason, controls and post-implementation review as a quasi-substitute for foresight become crucial. On this see below, text to notes 201-203.

${ }^{161}$ An event study based on the Business Roundtable's challenge even found that firms that were potentially the most affected by the proposed proxy access would have increased their market value 
comments, studies, and academic literature and provided detailed cost-benefit projections. Ultimately, however, the SEC reached the limits of what was quantifiable, and the court seems to have faulted the SEC for exercising regulatory judgement, which however appeared necessary given the inconclusive evidence.

Conversely, there are reasons to question the UK and EU impact assessments' completeness and reliability. For instance, the UK government's assessment of executive remuneration reform costs and benefits may well have been overly optimistic, offered a mostly one-sided analysis and, moreover, was built on a comparatively thin factual basis. To be more specific, in terms of costs, even if it turns out that after a phase of transitory costs there will be no additional and longer-term direct monetary expenses, companies will have less flexibility to design remuneration packages that are effective in appointing the most sought after executives, which was not properly taken into account. This effect is perhaps part of the desired 'dampening' of pay levels, but it remains a threat that should have been explicitly acknowledged. On the benefits side, the positive impacts of the reforms are not as clear as the RA suggests. For instance, greater transparency will likely only be felt by institutional investors, as it was at one point already conceded by the government. ${ }^{162}$ It is also doubtful whether the relatively minor changes in disclosed data and structure of reported remuneration information will ultimately have any significant positive consequences. Moreover, the assessments failed to engage with criticisms

under the new regime. See Bo Becker et al., 'Does Shareholder Proxy Access Improve Firm Value? Evidence from the Business Roundtable Challenge' (2013) 56 Journal of Law and Economics 127. ${ }^{162}$ See BIS, n 128 above, 19. 
suggesting potentially negative impacts of increased disclosure on pay levels as well as with research that cautions against placing greater emphasis on shareholders' say on pay. ${ }^{163}$ Indeed, both measures - disclosure and say on pay - have been plausibly linked with negative effects. Say on pay, in its previous shape as an advisory vote for shareholders, has not reversed the trend to increasing executive pay packages and may even have lead to efficiency losses. ${ }^{164}$ Based on early indicators, the new mandatory vote on executive pay regime is also unlikely to change this trend. ${ }^{165}$ An even bigger source of concern are claims

${ }^{163}$ On disclosure, see Ben-Shahar \& Schneider, n 11 above; A. Dignam, 'Remuneration and Riots: Rethinking Corporate-Governance Reform in the Age of Entitlement' (2013) 66 Current Legal Problems 401; B. E. Hermalin \& M. S. Weisbach, 'Information Disclosure and Corporate Governance' (2012) 67 Journal of Finance 195. On say on pay, R. Correa \& U. Lel, 'Say on Pay Laws, Executive Compensation, CEO Play Slice, and Firm Value around the World' (2013/14) International Finance Discussion Article,

http://www.federalreserve.gov/pubs/ifdp/2013/1084/ifdp1084.pdf (finding that only advisory say on pay votes, but not mandatory ones, tightened executive pay performance sensitivity); G. Ferrarini et al, 'Executive Remuneration in Crisis: A Critical Assessment of Reforms in Europe' (2010) 10 Journal of Corporate Law Studies 73, 86-88, 111; J. N. Gordon, “"Say on Pay”: Cautionary Notes on the U.K. Experience and the Case for Shareholder Opt-in' (2009) Harvard Journal on Legislation 323. For a critical discussion of both aspects, see D. Kershaw, Company Law in Context (Oxford: OUP, 2012) 303-04.

${ }^{164}$ Gordon, n 163 above, 344-45.

${ }^{165}$ See Petrin, n 115 above, 202. 
that pay disclosure leads to higher pay levels. ${ }^{166}$ Thus, in light of existing grave concerns against the two key features of the UK's strategy to regulate executive remuneration, a thorough RA should have included an in-depth discussion of these potential obstacles which was not the case.

Similarly, the impact assessment of the EU's non-financial disclosure rules raises several questions. First, given the lack of details on how benefits were assessed, how realistic is it that the mandatory part of the new regime, with its small projected costs, will result in benefits that are as large and broad in scope as the assessment assumed? The more extensive voluntary disclosures are more promising in this sense, although they are also far more costly. In any event, as already outlined above, the expected benefits were not quantified and there was no trustworthy data to make these projections. Second, there is the question of how reliable the regulator's assumption is that non-financial performance or CSR improve financial performance. Apart from a cursory reference to 'academic research', the assessment did not include details on the evidence it relied on in this regard.

Overall, therefore, the challenge for regulators and, if they are reviewing RA, courts lies in balancing expectations in terms of projecting and quantifying the consequences of regulatory initiatives against the practical difficulties in doing so. While acknowledging inherent limitations is important, regulators should also avoid falling into the trap of overestimating benefits and underestimating costs and failing to discuss countervailing evidence. From a more technical standpoint, other options to mitigate problems related to

\footnotetext{
${ }^{166}$ See, for example, Dignam, n 163 above, who makes a convincing argument that transparency initatives in particular have fuelled rather than dampened 'elite pay'.
} 
quantification include further refinement of the methods used in RA. It has been suggested that in complex, difficult to quantify areas tools such as multi-criteria analysis or breakeven (threshold) analysis are superior compared to traditional CBA. ${ }^{167}$ However, even these tools contain speculative elements and would continue to require regulators to assign values to uncertain impacts, which might be problematic, unfeasible, and even misleading.

Thus, in certain cases it can be more prudent for regulators to follow an approach similar to the SEC's approach in its analysis of the US Conflict Minerals Rule. There, the SEC stated in part that it was unable to readily quantify the rule's social benefits, remarking that they were 'quite different from the economic or investor protection benefits that our rules ordinarily strive to achieve.' ${ }^{168}$ In a decision by the D.C. Circuit on this same rule, the court confirmed this sentiment, finding that 'an agency is not required "to measure the immeasurable",. ${ }^{169}$ Still, regulators should not be quick to assume that something is, in fact, immeasurable and make good faith efforts at quantification.

${ }^{167}$ See, for example, Renda et al., n 17 above, 203; C. R. Sunstein, 'The Limits of Quantification' (2014) 102 California Law Review 1369. In the US, Circular A-4 (n 15 above) explicitly states that where non-quantified factors are likely to be important, regulator should use break-even analysis. 16877 Fed. Reg. 56,274, 56,342, 56,335 (2012). In line with section 13(p) of the Securities Exchange Act of 1934, the SEC rules require certain issuers to disclose annually information on their use of minerals originated in the Democratic Republic of the Congo or an adjoining country. ${ }^{169}$ National Association of Manufacturers v. SEC, 748 F.3d 359, 369 (D.C. Cir. 2014). Of course, a lesser degree of quantification may result in assessments that are akin to 'promotional' tools to persuade the public. This can be countered by placing more weight on thorough and discursive RA 


\section{(B) Contentious issues}

The discussion of difficulties stemming from complexity and quantifiability leads over to another problem. Not being able to (precisely) predict and quantify future costs, benefits, or impacts does not render RA useless. However, in situations where these issues are prevalent, another issue comes to the forefront - in the absence of reliable, non-conflicting evidence or data, what should guide RA and justify choices of preferred regulatory options?

In this vein, a major difficulty with RA in corporate law is its use as a basis for regulators to decided highly contentious issues of corporate governance that are not amenable to regulatory analytical tools. For example, from the case studies discussed above, we can see that the SEC - although explicitly acknowledging conflicting empirical evidence and sharply divided comments - posited that proxy access and, as an extension, shareholder representation on boards, contributes to positive firm performance. The UK government concluded that there is a market and regulatory failure in executive pay and that there is a need to intervene and strengthen the role of shareholders in the remunerationsetting process. Finally, as evidenced by non-financial disclosure rules in the EU, regulators have further ventured into the shareholder-stakeholder debate, finding that CSR benefits businesses financially and suggesting at least indirectly that corporate duties extend in part to third parties other than shareholders.

The point of this article is not to comment on the substance of these issues, but rather to highlight the role of RA. In this respect, those conducting RA should proceed with care that explores the knowledge base from multiple angles and is subject to external reviews. On this, see text to notes $000-000$ and $000-000$. 
when faced with fundamental issues that are not supported by clear data and subject to unresolved discussions in academic or other expert circles. Indeed, as two commentators have noted regarding the specific sub-problem of contradicting evidence in RA, 'when academics using proper research methods have come to conflicting conclusions about empirical results, it is quixotic for agencies and courts to endeavor to find one true answer. ${ }^{170}$ Yet, this does not mean that no action can be taken or that conclusive evidence of an intervention's impact has to be presented. As Sunstein remarked, '[with] cost-benefit analysis, it is at least possible to know what people are disagreeing about' ${ }^{171}$ This is true for RA more generally. To preserve RA's usefulness, however, regulators need to engage with views that diverge from their own position and be transparent about uncertainties, limitations, and any regulatory values or judgments that informed the analysis.

Comparing the SEC's proxy access CBA and the UK and EU's impact assessments relating to executive remuneration and non-financial disclosure, respectively reveals that the SEC's analysis is more thorough and extensive ${ }^{172}$ and includes more in-depth engagement with diverging views. In contrast, the UK and EU's impact assessments discussed in this article tend to frame the problem mostly from one point of view, with little to no space dedicated to opposing arguments and evidence. In the assessment of UK executive remuneration rules, for instance, it would have been useful to discuss shareholder empowerment as the underlying fundamental corporate governance question. The

\footnotetext{
${ }^{170}$ Hayden \& Bodie, n 11 above, 125.

${ }^{171}$ Sunstein, n 152 above, 267.

${ }^{172}$ See, for example, n 104 above and accompanying text.
} 
assessment does not grapple with research that questions shareholders' ability to be engaged and long-term oriented corporate stakeholders, ${ }^{173}$ suggestions that shareholders themselves may be part of the executive remuneration problem, ${ }^{174}$ or potential new issues related to the shifting of powers to proxy vote advisors. ${ }^{175}$ The impact assessment pertaining to EU non-financial disclosure rules, for its part, lacks a discussion of research contradicting the assessment's position that non-financial disclosure and CSR lead to better financial performance. ${ }^{176}$

Indeed, concerning the UK, studies have already identified various weaknesses, including narrow consultation processes, evidence that assessments were conducted outside

${ }^{173}$ See, for example, B. R. Cheffins, 'The Stewardship Code's Achilles' Heel' (2010) 73 Modern Law Review 1004; J. Kay, 'Kay Review of UK Equity Markets and Long-Term Decision-Making' (July 2012).

${ }^{174}$ C. Villiers, 'Controlling Executive Pay: Institutional Investors or Distributive Justice?' (2010) 10 Journal of Corporate Law Studies 309, 341.

${ }^{175}$ See S. M. Bainbridge, Corporate Governance after the Financial Crisis (New York: OUP, 2012) 133-134; D.F. Larcker et al., 'Outsourcing Shareholder Voting to Proxy Advisory Firms' (last updated 2014) Rock Center for Corporate Governance at Stanford University Working Paper No 119, available at http://papers.ssrn.com/sol3/papers.cfm?abstract_id=2101453 (suggesting decreases in shareholder value).

${ }^{176}$ A recent example is H. Servaes \& A. Tamayo, 'The Impact of Corporate Social Responsibility on Firm Value: The Role of Customer Awareness' (2013) 59 Management Science 1045, which find a neutral or negative relation between CSR and firm value for businesses with low customer awareness. 
of or after the policy development process, and insufficient provision or even omission of significant evidence. ${ }^{177}$ In particular, UK impact assessments accompanying the implementation of EU policies are often produced after a decision has been made at the EU level, thereby severely limiting the potential scope and utility of domestic impact assessments. ${ }^{178}$ These weaknesses are worrying and raise reliability concerns. ${ }^{179}$

The relative lack of critical engagement in the UK and EU is to some extent logical given that in these jurisdictions RA is embedded in the political decision-making process. Policies such as mandatory say-on-pay provisions or non-financial disclosure need to be understood against the background of broader political goals. For example, non-financial disclosure is based on the EU's corporate governance plan and is in line with the EU's support for a stakeholder approach, which emphasises the need for - and benefits associated with - corporations to act in a socially responsible manner. The UK's (and the EU's) executive remuneration policies are part of the evolving shareholder democracy

${ }^{177}$ See National Audit Office, n 149 above; OECD, n 77 above. See also D. Russel \& J. Turnpenny, 'The politics of sustainable development in UK government: what role for integrated policy appraisal?' (2009) 27 Environment and Planning C 340, 341 (echoing concerns that impact assessments 'were ex post justifications of predetermined decisions rather than ex ante appraisals to drive policy development').

${ }^{178}$ National Audit Office, n 149 above, 8.

${ }^{179}$ Yet, it is worth noting that these types of serious issues are, by design, not taken into account in emerging 'scorecard' type methods of evaluating the quality of RA. For an example of this approach, see O. Fritsch et al., 'Comparing the content of regulatory impact assessments in the UK and EU' (2013) Public Money \& Management 445. 
movement, with the UK and EU having long committed to shareholder empowerment or 'real shareholder democracy' as being an integral part of their corporate governance framework and an important political goal. ${ }^{180}$

While there is certainly value to be had from policies that are based on longer-term strategic planning, regulators should ensure that RA documents clearly reference these background contexts, thereby avoiding the impression that a proposed set of provisions is solely based on the weighing of costs and benefits - or positive and negative impacts - in the specific case. This would also facilitate the process of RA, freeing the actors that engage in it to acknowledge uncertainties and controversies but still go ahead with a policy by explaining the broader principles and aims that it supports. Alternatively, however, it would be even more desirable if RA could challenge these ingrained regulatory logics, instead of confirming them. However, at least in the corporate area, this is not presently the case. Indeed, given the above mentioned issues, RA is more in danger of becoming a form of rhetoric designed to advance already selected policy positions that are based on empirically ungrounded assumptions.

A related but distinct issue is that RA may also serve as a tool to confirm pre-existing beliefs on the part of regulators (and the public). In particular, despite its potential to mitigate such problems, ${ }^{181}$ RA may suffer from varying degrees of underlying confirmation bias. Decision-making experts such as Daniel Kahnemann have suggested that in order to

\footnotetext{
${ }^{180}$ For example, see European Commission, 'Modernising Company Law and Enhancing Corporate Governance in the European Union - A Plan to Move Forward' COM(2003) 284, 14.

${ }^{181}$ See 000-000 above.
} 
overcome inherent biases, decision-makers should among others aim to explore dissenting opinions and views, explore credible alternatives, and be cautious about making overly optimistic forecasts. ${ }^{182}$ Similarly, this would also assist in countering public biases and regulatory positions and logics. Executive remuneration, for instance, is particularly prone to lead the public to false assumptions about its relative importance for shareholders, and the economy at large. Remuneration is typically small relative to a company's overall value, meaning that reductions in pay awards are unlikely to affect share prices. ${ }^{183}$ Additionally, the impact of changes in the size and design of remuneration packages on company value is far from clear, not to mention that high salaries in non-corporate areas (such as in the entertainment industry or sports) remain largely unquestioned.

Theoretically, in the jurisdictions considered in this article, RA is already designed along the lines of such considerations. Nevertheless, there is room left for improvement in practice. Using the UK as an example, RA should be conducted at an early stage in the regulatory process to maximise its influence, consultation outcomes should be taken into account in greater depth, and evidence bases and analyses should be deepened. ${ }^{184}$

${ }^{182}$ See D. Kahnemann et al., 'The Big Idea: Before You Make That Big Decision...' (2011) 89 Harvard Business Law Review 51.

${ }^{183}$ See, for example, A. Lund, 'Say on Pay’s Bundling Problems' (2011) 99 Kentucky Law Journal 119, 136 n 5 (referring to the 'relatively small magnitude of executive compensation relative to most firms' balance sheets). For a critical take on executive remuneration in general, see M. Dorff, Indispensable and Other Myths: Why the CEO Pay Experiment Failed and How to Fix it (Berkeley et al: University of California Press, 2014).

${ }^{184}$ Additional details are discussed below, 000-000. 
Generally, the solution to decision-making in contentious areas and in the face of potential biases lies in transparency, the willingness to acknowledges uncertainties, concerted efforts to develop an informed, balanced view, and willingness on the part of regulators to accept RA outcomes that suggest that no action or an action that is contrary to what initially had been proposed should be taken. Moreover, in highly debated areas, legislative guidance may be needed in determining which variables RA should examine and, in particular, whose benefits should be prioritised. In corporate law, one of the questions that may arise (and could be addressed by the legislature) is whether the interests of investors, managers, consumer, other stakeholders, or society at large should be at the centre of a new policy initiative. Relatedly, the question may arise whether costs of regulated businesses should be weighed against benefits accruing to investors, other stakeholders, or society at large. ${ }^{185}$

Finally, another tool for countering confirmation biases is judicial review. While this has not been a major factor in Europe, it has drawn considerable attention in the US. Nevertheless, the question remains how a court can - and indeed why it should - make potentially far reaching decisions on contentious corporate governance questions. In this vein, some US commentators have already suggested limiting judicial oversight to reduce legal uncertainty and balancing it with increased statutory directives and legislative power over agencies. ${ }^{186}$ Indeed, strengthening the RA process, in conjunction with targeted ${ }^{185}$ For an in-depth discussion, see Y. A. Lee, 'The Efficiency Criterion for Securities Regulation: Investor Welfare or Cost-Benefit Analysis?' (2015) 57 Arizona Law Review 85.

${ }^{186}$ See Fish, n 111 above, 727, 730; J. C. Coffee, Jr., 'The Political Economy of Dodd-Frank: Why Financial Reform Tends to be Frustrated and Systemic Risk Perpetuated' (2012) 97 Cornell Law 
guidance by democratically legitimised legislative bodies in appropriate cases, seems to represent a superior approach than reliance on intervention by courts.

\section{(B) A revised view - RA as process}

Given the challenges of RA in corporate law, the question arises what remains in terms of value for this tool and what its future role should be. To elucidate this question, we should first recall the reasons for having RA in the first place. As discussed, major justifications, particularly form a US perspective, include those that focus on efficiency, social welfare, reduction of cognitive biases, and priority setting. It has also been noted - as a criticism or positive aspect, depending on the viewpoint - that RA slows down the regulatory process.

In the corporate context, it is questionable whether or to what extent these major functions are applicable. Without reliable data and given the difficulties in predicting the precise impact of proposed regulations, achieving efficiency is a goal that is hard to achieve, with the same being true for overall well-being. Moreover, RA is theoretically well-suited to reduce cognitive biases on the part of the public and regulators. With regards to the latter, however, existing weaknesses in RA procedures and various interconnections with political agendas suggest that RA is not the neutral, analysis-driven tool that it appears to be. Furthermore, there is also no clear evidence showing that RA influences regulatory pace or limits regulatory intervention. If used as a promotional tool, RA may even

Review 1019, 1080. See also Coates, n 6 above; D.M. Nagy, 'The Costs of Mandatory Cost-Benefit Analysis in SEC Rulemaking' (2015) 57 Arizona Law Review 129 (both arguing against US proposals to impose certain forms of mandatory CBA on rulemaking agencies). 
contribute to more, rather than less, regulation, especially where benefits are emphasised over costs or negative impacts. As seen in the examples discussed above, the proposition that RA favours the status quo is therefore not generally accurate.

However, RA also has the potential to increase transparency and information, facilitate monitoring of regulators, and provide factors for decision-making. These functions, although they are not without their own challenges, provide a sounder basis going forward in thinking about RA in corporate law and also offer a compelling argument in favour of RA. Taking a view that stands between approaches that promote strictly cost-benefit and efficiency driven regulation and those that reject this very idea, this article suggests that RA should be understood not as being dependent on a specific normative criterion - such as efficiency, social welfare, better 'quality', etc. - but as an iterative process. Thus, RA is less about providing substantive answers and should be conceptualised primarily as an informational tool for the public and regulators, who can see the reasoning and evidence behind regulatory action and are provided with participatory opportunities. RA thereby also contributes to transparency and monitoring of regulators. Viewed this way, and contrary to what some critics believe, RA is a useful tool, albeit in ways that differ from what it is commonly expected to achieve.

As discussed, RA is not identical with strict cost-benefit analysis and does not necessarily result in net beneficial rules in the traditional, economic sense. The exact details in this regard depend on the statutory or other basis on which RA is conducted, but at least where regulators are directed to 'consider' costs and benefits or 'assess' the impacts of a policy, it is mistaken to expect a rigid cost-benefit analysis. Where traditional CBA is used, 
it should act as a guide, but not trump other considerations. ${ }^{187}$ Generally, policies should pass a cost-benefit analysis or have positive impacts that outweigh negative impacts. However, should this not be the case a policy may still be recommended, although this requires detailed explanations, stating the reasons for the decision, ${ }^{188}$ which could be related to public policy or specific distributive considerations. In the corporate law context, for instance, the government could see compelling reasons for wealth distributions from one constituency to another constituency. ${ }^{189}$ For instance, a rule might transfer wealth from managers to shareholders, potentially even without creating new value or reducing cost. In such and similar scenarios (and whether one agrees with the rule's policy thrust or not), thorough explanations of a policy's underlying considerations are preferable over regulators having to justify their actions strictly based on cost-benefit ratios or prevalence of positive impacts, which invites biased assessments.

This article thus stands in contrast to criticisms such as by Jeffrey Gordon, who views CBA in financial regulation as 'a serious category mistake' and 'conceptually wrongheaded'. ${ }^{190}$ The claim made here is that RA in the corporate context - including CBA

${ }^{187}$ See also Ahdieh, n 45 above, 2071, who distinguishes between economic analysis and policy choice, opining that while regulators should be expected to conduct rigorous CBA, their ultimate regulatory choices should not be limited to the outcomes dictated by that analysis.

${ }^{188}$ See Hahn \& Sunstein, n 12 above, 1495-1499, 1527-1529 (suggesting, among others, that regulators should not be bound by bottom-line numbers and that in certain cases qualitative considerations and distributive impacts may justify policies that have higher costs than benefits).

${ }^{189}$ See Lee, n 185 above, 88.

${ }^{190}$ Gordon, n 22 above, 352. 
as one of its elements - is a useful tool, albeit in ways that differ from what it is commonly expected to achieve, including the idea that RA should support a particular normative criterion. The approach suggested herein acknowledges the need for regulatory flexibility, similar to what Jeffrey Gordon refers to as the 'pragmatics of regulatory judgment' ${ }^{191}$ Yet, while Gordon rejects CBA and calls for an entirely 'different regulatory model ${ }^{192}$ based on these pragmatics, this article's position is that CBA remains an important, albeit not decisive, element of RA, which should combine quantification and 'pragmatics'.

Gordon's 'regulatory judgment' is akin to what regulators and other academics have also referred to as 'professional judgment' or 'expert judgment'. In recent work, John Coates makes the point that expert judgment is an unavoidable component of quantified CBA given that this tool is bound to produce unreliable results. However, at the same time he also stresses that experts can - and often do - err in their judgment. ${ }^{193}$ In order to improve what he perceives as a weak status quo, Coates therefore focuses on improvements to CBA as a method, including how to account for the costs and benefits of CBA itself. Coates puts hardly any weight on informational and procedural benefits of CBA (and RA in general), the exception being transparency, which however is only discussed in terms of

\footnotetext{
191 ibid 375.
}

192 ibid. Although Gordon suggests that regulators should not 'give up on the project of applied consequentialism', he maintains that 'the critical judgments ought not to be made on the basis of [CBA] but rather in light of normative principles.' ibid 374.

193 Coates, n 6 above, 903-904. See also Sunstein, n 152 above (suggesting decision-making strategies for agencies when quantification of costs/benefits and break-even analyses are not feasible); Office of Management and Budget, Circular A-4, above n 15. 
precision and reliability in conducting CBA. ${ }^{194}$ Coates' critique of CBA is so severe that it has been interpreted to mean that 'regulators should not engage in CBA' ${ }^{195}$ Although this is incorrect - Coates argues for an improvement, not abandonment of CBA - it remains unclear what he suggests as the way forward given that he believes that CBA will produce unreliable results for the foreseeable future but also sees alternative modes of evaluation and expert judgment as flawed and inferior to reliable CBA.

The common theme in Gordon's and Coates' work is that they identify weaknesses in corporate/financial law CBA. As a result, the proposed course of action is to either abolish CBA (Gordon) or to mostly refrain from using it until it is improved, although with unclear implications (Coates). While improvements to CBA would obviously be a welcome development, the approach proposed in this article presents a third way, one in which these weaknesses are not fatal as the function of RA is seen as going beyond quantification. Regulators that engage in good faith efforts to quantify and assess regulatory impacts, and consult with interested parties, still contribute to RA's beneficial informational and transparency functions. With the appropriate disclosures, this is true even when RA evaluates alternatives and helps design the details of what in reality may well relate to policies whose main thrust has already been decided upon. Admittedly, the informational function emphasised herein is put at risk by distorted information and biases that affect RA. However, these issues can be mitigated through other measures suggested herein, including

\footnotetext{
${ }^{194}$ More precise quantification should lead to enhanced transparency and vice versa. See Coates, n 6 above, 888, 889-890.

${ }^{195}$ Posner \& Weyl, n 7 above, 246.
} 
a relaxed focus on quantification, enhanced transparency and deeper engagement, and external inputs during and after the RA process. ${ }^{196}$

Accepting - or, in Gordon's case, demanding - the inclusion of regulatory judgment in RA invokes yet another issue: the question of independence between the technocratic regulatory and political sphere. ${ }^{197}$ One response in reforming RA could be to call for a stronger decoupling from politics. While value neutral policy-making may represent a realistic and aspirational goal in other fields, it is uncertain whether this would be desirable and, indeed, practically possible in corporate law. ${ }^{198}$ 'Regulatory' or similarly labelled judgements are bound to contain varying degrees of political judgments. Given the constraints outlined above, completely value neutral decision-making purely based on expected regulatory effects remains illusory and may not even be desirable or in accordance with democratic principles that mandate governments to pursue certain policies. Thus, these systemic realities should be accepted since it is not that they are truly troubling, but rather

${ }^{196}$ See 000-000 and 000-000.

${ }^{197}$ On this and the concept of 'rational policy-making' see Radaelli \& de Francesco, n 1 above.

198 See also text to $\mathrm{n} 180$ above. On the interconnections between politics and corporate (governance) law, see generally M. Roe, Strong Managers, Weak Owners: The Political Roots of American Corporate Finance Law (Princeton: Princeton University Press, 1994); P.A. Gourevitch \& J. Shinn, Political Power and Corporate Control: The New Global Politics of Corporate Governance (Princeton: Princeton University Press, 2005); C. Bruner, Corporate Governance in the Common-Law World (Cambridge et al.: CUP, 2013). As two commentators have noted, corporate law may also contain a 'folkloristic' element. M. Kahan \& E. B. Rock, 'Symbolic Corporate Governance Politics' (2014) 94 Boston University Law Review 1997. 
instances where RA is used to mask these realities. Indeed, criticisms of RA's alleged antiregulatory tendency are imprecise - in truth, the issue that these criticisms apparently decry is that RA may be used to hide politically motivated decisions. ${ }^{199}$

Having framed RA more heavily in terms of its procedural and informational functions, some important guiding themes emerge. Those conducting and using RA should quantify and engage in economic analysis but, at the same time, be given sufficient leeway to exercise judgement, which would also alleviate at least some of the problems related to the formal or informal requirement to quantify costs, benefits, or impacts. They should also be allowed to define, to an appropriate extent, the fine line between economic analysis and policy choice. ${ }^{200}$ In return, those in charge of RA also need to strive for an encompassing, open-minded, transparent, and engaged process, which maximises meaningful third party input and avoids using RA as camouflage.

For instance, current procedures could be bolstered by introducing ex ante control in the form of stringent independent studies and quality checks. Depending on the importance of an initiative, this could be conducted through independent intra-governmental bodies and additionally through outside panels comprised of experts with different backgrounds and

${ }^{199}$ To clarify, RA in the EU is by design clearly subordinated to political decisions, meaning that its outcome or finalised assessment is a political decision-making aid. However, the judgment referred to in this paragraph is judgment exercised as part of the RA process, where its occurrence might come as a surprise given that RA appears to be of a purely objective, impact-driven (or cost-benefit driven) nature. Yet, it is already in this first layer where RA may be influenced by politics and policy. See also Lianos \& Fazeka, n 54 above, 8-12 (discussing impact assessments and politics). ${ }^{200}$ With regards to the SEC's rulemaking, see Kraus \& Raso, n 112 above. 
viewpoints. These bodies and panels' scrutiny and normative assessment of proposed policies should go far beyond what can be seen in studies such as the one commissioned as part of the EU's non-financial disclosure rules process. ${ }^{201}$ Additionally, the EU and UK should strive for deeper engagement with comments received during the consultation phase, which also ties in to the point made earlier regarding the need for greater critical analysis in these jurisdictions' RA process.

Moreover, ex post control mechanisms should be further strengthened and used to implement appropriate tweaks and changes to recently adopted policies. Implementation reviews and re-assessments based on newly available information and surveys, as in part already envisaged in the jurisdictions discussed herein, are the correct starting point. ${ }^{202}$ These reviews could be further extended, such as by using external peer reviews, ${ }^{203}$ particularly in the area of highly contentious or uncertain fields of policy-making. In short, with the substantive methods of how to conduct RA already being at a comparatively

${ }^{201}$ CSES, n 144 above, which assessed quantified costs and benefits based on a small number of responses from businesses that responded to a questionnaire.

202 Roberta Romano has formulated a farther reaching 'sunset' proposal for certain financial regulation policies, which she suggests should be phased-out unless re-enacted by regulators. R. Romano, 'Regulating in the Dark', in: C. Coglianese, ed., Regulatory Breakdown: The Crisis of Confidence in U.S. Regulation (Philadelphia: University of Pennsylvania Press 2012). For a critique of this, see Coffee, n 186 above.

${ }^{203}$ See K. Arrow et al., Benefit-Cost Analysis in Environmental, Health, and Safety Regulation (AEI: Washington, D.C, 1996) 9. 
advanced stage, increased efforts spent on improving RA procedure appear more goaloriented and will likely lead to larger incremental improvements going forward.

\section{(A) CONCLUSION}

RA has significant potential to support the regulatory process. Examining the field of corporate law and focusing on three recent case studies, however, this article has argued that RA does not live up to several important expectations that regulators and commentators often ascribe to this tool. In the corporate context, namely the promises of efficiency, social welfare, and reduced biases through RA tend to be thwarted by problems relating to prediction and quantification of future events as well as the general inability of traditional RA to be an appropriate arbiter of disagreements over fundamental corporate governance questions. These flaws may prove fatal for the accuracy of the whole exercise of conducting RA and endanger its utility and credibility.

Inherent uncertainties, false certainty, and the potential for camouflage and promotional overreach signify that the traditional view of RA needs to be adjusted. While improving the substance of RA remains a valid goal, the political nature of many important corporate law issues also signifies the need for RA to incorporate leeway for properly disclosed and reasonable regulatory judgments. Thus, properly understood, the function of RA is in great part procedural in nature, which is why procedure - namely in the form of consultation, critical engagement, clarity in underlying goals, and review - needs to be RA's major focal point. While this may not directly result in the most efficient or 'best' policies, it will facilitate information, transparency, and monitoring. Ultimately, however, RA strengthened along these lines will indirectly lead to more reasoned and legitimised corporate law policies. 